\title{
Evaluation of Advanced Receiver Autonomous Integrity Monitoring Performance on Predicted Aircraft Trajectories
}

\author{
S. Paternostro, T. Moore, C. Hill \\ Nottingham Geospatial Institute (NGI) \\ University of Nottingham \\ Nottingham, United Kingdom \\ simone.paternostro@nottingham.ac.uk
}

\author{
J. Atkin, H.P. Morvan \\ Institute for Aerospace Technology (IAT) \\ University of Nottingham \\ Nottingham, United Kingdom
}

\begin{abstract}
The development of new GNSS constellations, and the modernization of existing ones, has increased the availability and the number of satellites-in-view, paving the way for new navigation algorithms and techniques. These offer the opportunity to improve the navigation performance while at the same time potentially reducing the support which has to be provided by Ground and Satellite Based Augmented Systems (GBAS and SBAS). These enhanced future capabilities can enable GNSS receivers to serve as a primary means of navigation, worldwide, and have provided the motivation for the Federal Aviation Administration (FAA) to form the GNSS Evolution Architecture Study (GEAS). This panel, formed in 2008, investigates the new GNSS-based architectures, with a focus on precision approach down to LPV-200 operations. GEAS identified ARAIM as the most promising system. The literature, produced through a series of studies, has analysed the performance of this new technique and has clearly shown that the potential of ARAIM architectures to provide the Required Navigation Performance for LPV 200. Almost all of the analysis was performed by simply studying a constellation's configuration with respect to fixed points on a grid on the Earth's surface, with full view of the sky, evaluating ARAIM performance from a geometrical point of view and using nominal performance in simulated scenarios lasting several days
\end{abstract}

In this paper, we will evaluate the ARAIM performance in simulated operational configurations. Aircraft flights can last for hours and on-board receivers don't always have a full view of the sky. Attitude changes from manoeuvers, obscuration by the aircraft body and shadowing from the surrounding environment could all affect the incoming signal from the GNSS constellations, leading to configurations that could adversely affect the real performance. For this reason, the main objective of the algorithm developed in this research project is to analyse these shadowing effects and compute the performance of the ARAIM technique when integrated with a predicted flight path using different combinations of three constellations (GPS, GLONASS and Galileo), considered as fully operational.

Keywords- Advanced Receiver Autonomous Integrity Monitoring (ARAIM); Global Navigation Satellite System (GNSS); performance prediction; aircraft trajectory; shadowing

\section{INTRODUCTION}

Receiver Autonomous Integrity Monitoring (RAIM) is an approved civil aviation navigation system for Lateral
Navigation (LNAV) in the En-route, Terminal and Nonprecision approach flight phases and RAIM prediction is required if GPS is to be used to solely satisfy the RNAV requirements [1]. The main drawbacks of the RAIM technique are that it uses a single constellation, a single frequency and only has the capability of detecting a single fault, and these factors dramatically limit the performance. Advanced Receiver Autonomous Integrity Monitoring (ARAIM) aims to become an approved navigation system down to the LPV-200 approach level (Localizer Performance with Vertical Guidance, decision height of 200 feet and visibility of $1 / 2$ mile) in order to reduce the ground systems effort, to increase air traffic in minor airports and to allow curved and parallel approaches with reduced or limited visibility. The main strengths of ARAIM are that it can use multiple GNSS constellations, use dual frequency data and has a multiple fault detection capability. For this reason, one of the aims and main objectives of this research is to develop a system that satisfies the future needs of civil aviation. The final objective is to evaluate the influence of the attitude of the aircraft and the surrounding environment on ARAIM performance, since previous ARAIM performance analysis was mostly performed on selected points on the Earth's surface, with full view of the sky (no obstacles that can shadow satellites).

As previously mentioned, the FAA formed the GEAS panel to investigate new GNSS-based architectures with a focus on precision approach down to LPV-200 operations. In the first [2] and second [3] report, the GEAS identified ARAIM (Advanced RAIM) as the most promising system because it could reduce the cost of ground infrastructure and eliminate single points of failure (e.g. interference at the monitoring station). In these documents, the GEAS also defined the possible architecture, made assumptions and suggestions related to the Ground Monitoring requirements, the data link and the information that should be provided through the integrity message, the so-called Integrity Support Message (ISM). Moreover, it clearly stated the necessary performance requirements that ARAIM systems must satisfy to support LPV-200 capabilities; the following list summarises the most demanding requirements for GNSS systems:

- $\quad 4 \mathrm{~m} \mathrm{95 \%} \mathrm{accuracy} \mathrm{requirement:} \mathrm{the} \mathrm{probability} \mathrm{of} \mathrm{a}$ vertical error exceeding $4 \mathrm{~m}$ must be below $5 \%$. 
- The probability that the position error (horizontal and vertical) exceeds the protection level (PL) for longer than the Time-to-Alert (TTA), called the Probability of Hazardously Misleading Information (PHMI), should be less than $2 * 10^{-7}$ per approach:

$$
\mathrm{PHMI}=\sum \mathrm{p}_{\text {threats_i } \mathrm{i}} \mathrm{P}\left(\mathrm{VPE}>\mathrm{VPL} \text { or HPE }>\text { HPL }\left.\right|_{\text {threat } \mathrm{i}}\right) \leq 2 * 10^{-7}
$$

- $15 \mathrm{~m}$ Effective Monitor Threshold (EMT) requirement: the probability of an undetected fault resulting in a vertical position error exceeding $15 \mathrm{~m}$ must be less than $10^{-5}$ :

$$
\mathrm{P}(\mathrm{VPE} \geq 15 \mathrm{~m} \mid \text { fault }) \mathrm{P}(\text { fault }) \leq 10^{-5}
$$

- $\quad 8 * 10^{-6}$ continuity requirement: an approach at a given location and future time can only be declared available if there is a probability below $8 * 10^{-6}$ of not being able to complete it (under normal condition).

The EU/US Working Group C (WG-C) established a technical sub-group, for which the main objective was to define a reference multi-constellation ARAIM concept that allows vertical guidance worldwide. The outcome of this subgroup is the report [4] that fully describes a preliminary multiconstellation ARAIM algorithm based on the Multiple Hypothesis Solution Separation method. This was one of the first algorithms to implement multi-constellation RAIM with the possibility of multiple simultaneous failures across the constellations, presented in [5] and also used in [6], [7] and in [8], in which the authors developed an ARAIM algorithm with real-time dual frequency L1-L2 GPS flight data.

Most of the literature produced afterwards is based upon the algorithms developed in one of [8], [3], [4] or [9].

These preliminary analysis clearly show the potential of Advanced RAIM architectures to provide the Required Navigation Performance and achieve a global coverage of LPV-200 using, at least, two constellations, and was confirmed by other related research [10], [11], [12] and [13]. In [14] and [15], the authors analysed the algorithm performance in different constellation configurations (single, dual and triconstellation), highlighted the critical elements and proposed new approaches or possible improvements that they applied in a more developed algorithm, fully described in [16].

Fig. 1 and Fig. 2 show an example of the analyses performed by Stanford University with the Matlab Algorithm Availability Simulation Tool (MAAST) [17], , considering a single constellation configuration (Galileo) and dualconstellation (GPS and Galileo) [15].

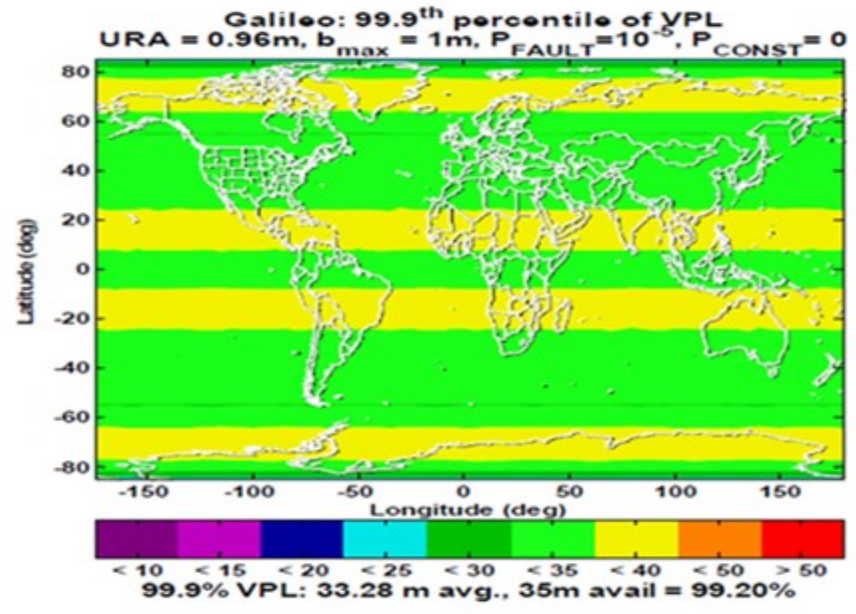

Fig. 1. 99.9 $9^{\text {th }}$ VPL percentile for ARAIM using the 27SV Galileo Constellation

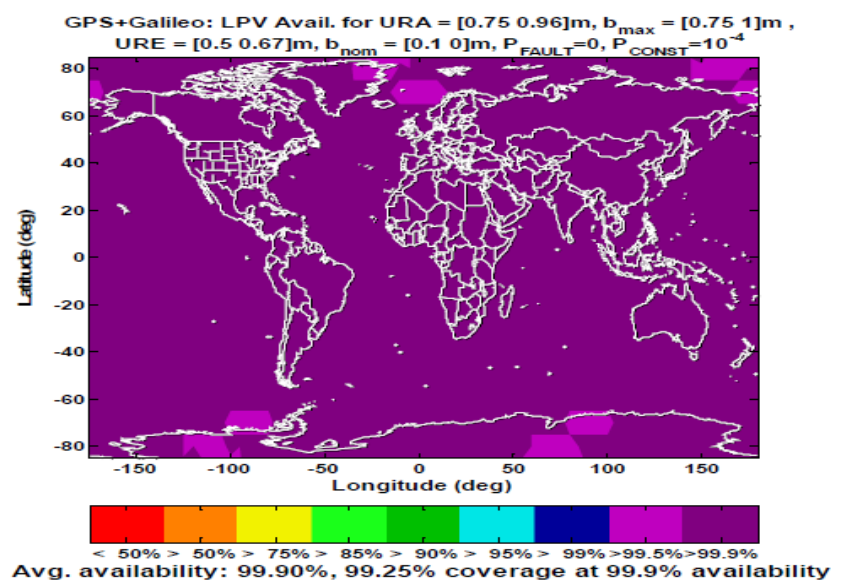

Fig. 2. Combined Availability for GPS + Galileo

However, in a real configuration, the aircraft attitude and the terrain and objects in the surrounding environment could shadow a certain number of satellites (Fig. 3), especially during a safety critical phase (take-off, maneuverings and landing phases), leading to a possible degradation of the integrity performance of the ARAIM algorithm. Aircraft routes and trajectories are predefined through a series of waypoints (Fig. 4) and, as mentioned before, RAIM prediction is required if GPS is to be used to solely satisfy the RNAV requirements [1].

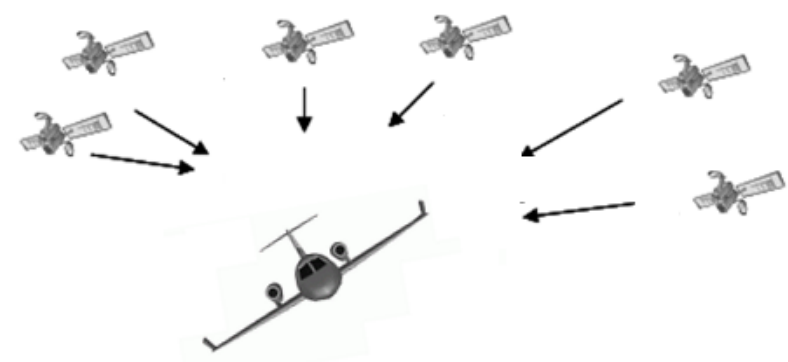

Fig. 3. Attitude shadowing effect 


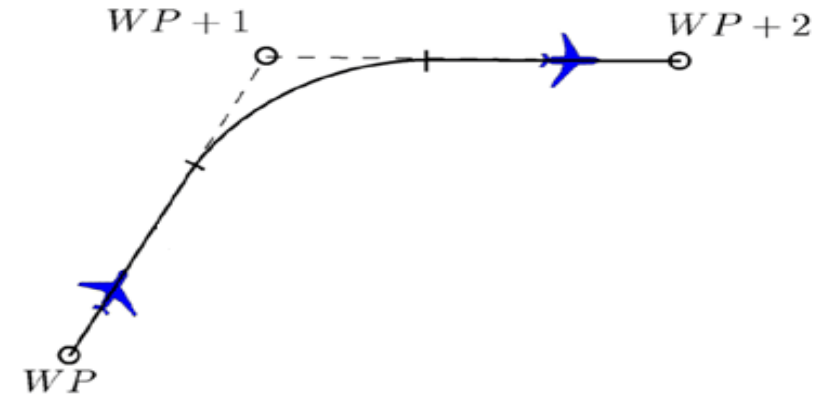

Fig. 4. Trajectory in terms of waypoints

None of the previous analysis considered and integrated into the system the effects of these two factors, only in [18] did the authors notice an effect on the ARAIM performance during flight tests.

This research has extended this requirement for a generic situation, analysing ARAIM performance prediction for different approach routes in several airports around the World in order to prove the concept. For the purpose of this research, the MAAST has been selected and modified in order to analyse ARAIM performance along aircraft trajectories considering the shadowing effect of the aircraft attitude and surrounding environments. The newly developed algorithm, named APPATT (ARAIM Performance on Predicted Trajectories Tool), has the main objective of computing the four parameter indices of the reliability of the navigation solution provided by GNSS.

The paper is organized as follow: in the first section the ARAIM algorithm and MAAST main functions will be briefly explained. This is followed by a description of the algorithms that have been developed. Algorithms are presented. Selected routes and test results are presented and discussed in the last chapter.

\section{ARAIM AND MAAST}

In this paragraph the ARAIM algorithm and MAAST developed by Stanford University will be briefly described, for further details please refer to [16] and [17]:

\section{A. Advanced Receiver Autonomous Integrity Monitoring (ARAIM) Algorithm}

The following paragraph explains the ARAIM algorithm functions used in this research, other functions, such as the Chi-Square test, the fault detection and exclusion or the computation of the integrity and accuracy after the detection of a fault, are not considered, since the main purpose of this research is to analyse the algorithm performance in nominal conditions and evaluate the influence of other factors that might reduce the reliability of the system. The main functions of the algorithm can be easily summarised in the following steps:

- Covariance Matrices. The first step of the ARAIM algorithm is the computation of the Covariance
Matrices for the two error models ( $C_{\mathrm{int}}$ for integrity and $C_{\text {acc }}$ for accuracy model) using the signal errors and biases characterisation of each satellite:

$$
\begin{aligned}
& C_{\mathrm{int}}(i, i)=\sigma_{\mathrm{URA}, i}^{2}+\sigma_{\text {tropo }, i}^{2}+\sigma_{\mathrm{user}, i}^{2} \\
& C_{\mathrm{acc}}(i, i)=\sigma_{\mathrm{URE}, i}^{2}+\sigma_{\text {tropo }, i}^{2}+\sigma_{\mathrm{user}, i}^{2}
\end{aligned}
$$

Where:

TABLE I.

DEFINITIONS

\begin{tabular}{|l|c|}
\hline \multicolumn{1}{|c|}{ Name } & Description \\
\hline$\sigma_{\mathrm{URA}, i}$ & $\begin{array}{c}\text { standard deviation of the clock and ephemeris error of } \\
\text { satellite } i \text { used for integrity }\end{array}$ \\
\hline$\sigma_{\mathrm{URE}, i}$ & $\begin{array}{c}\text { standard deviation of the clock and ephemeris error of } \\
\text { satellite } i \text { used for accuracy and continuity }\end{array}$ \\
\hline$\sigma_{\mathrm{tropo}, i}$ & $\begin{array}{c}\text { Tropospheric delay of satellite } i \text {, function of its } \\
\text { elevation angle }\end{array}$ \\
\hline$\sigma_{\mathrm{user}, i}$ & $\begin{array}{c}\text { User contribution to the error budget function of } \\
\text { satellite } i \text { elevation angle }\end{array}$ \\
\hline
\end{tabular}

- Computation of All-in-view Position Solution. Using a weighted least-squares estimation:

$$
\Delta x=\left(G^{T} W G\right)^{-1} G^{T} W \Delta P R
$$

Where:

TABLE II.

DEFINITIONS

\begin{tabular}{|l|c|}
\hline \multicolumn{1}{|c|}{ Name } & Description \\
\hline$\Delta x$ & $\begin{array}{c}\text { Corrections of the receiver position and clock states } \\
\text { Geometry Matrix in East North Up coordinates with a } \\
\text { clock component for each constellation }\end{array}$ \\
\hline $\mathrm{G}$ & Weighting matrix defined as $\mathrm{C}^{-1}$ int \\
\hline$\Delta P R$ & $\begin{array}{c}\text { Vector of pseudorange measurements minus the } \\
\text { expected ranging values based on the location of the } \\
\text { satellites and the position solution given by the previous } \\
\text { iteration }\end{array}$ \\
\hline
\end{tabular}

- Determination of the faults that need to be monitored. Each satellite and constellation is characterised by a probability of failure; the algorithm evaluates the maximum number of simultaneous satellites or constellation faults that need to be considered through the computation of the probability of all the possible subsets. The subset probabilities that exceed a predefined threshold need to be monitored.

- Fault-tolerant positions and associated standard deviation and biases. For each of the $k$ subsets the algorithm computes the position solution $x^{(k)}$, evaluates the differences with the all-in-view position solution $x^{(0)}$ and determines the standard deviations and the test thresholds.

$$
\Delta x^{(k)}=x^{(k)}-x^{(0)}=\left(S^{(k)}-S^{(0)}\right) y
$$


Where

$$
S^{(k)}=\left(G^{T} W^{(k)} G\right)^{-1} G^{T} W^{(k)}
$$

$y$ : vector of pseudorange measurements minus the expected range for an all-in-view position.

The variances of $x^{(k)}{ }_{q}$ (where index $q=1,2$ and 3 designate the East, North and Up components respectively) are given by:

$$
\sigma_{q}^{(k) 2}=\left(\left(G^{T} W^{(k)} G\right)^{-1}{ }_{q, q}\right.
$$

The nominal biases of the position solutions $x^{(k)}{ }_{q}$ are given by:

$$
b_{q}^{(k)}=\Sigma_{i}\left|S_{q, i}^{(k)}\right| \mathrm{b}_{\text {nom,i }}
$$

The variances of the differences $\Delta x^{(k)}{ }_{q}$ are given by:

$$
\sigma_{s s, q}^{(k) 2}=e_{q}^{T}\left(S^{(k)}-S^{(0)}\right) C_{a c c}\left(S^{(k)}-S^{(0)}\right)^{T} e_{q}
$$

in which $e_{q}$ denotes a vector whose qth entry is one and all others are zero

- Solution Separation Threshold. Each fault mode has three solution separation threshold tests, one for each coordinate. They are defined by:

$$
T_{k, q}=K_{f a, q} \sigma_{s s, q}^{(k)}
$$

Where:

$$
\begin{gathered}
K_{f a, 1}=K_{f a, 2}=Q^{-1}\left(P_{F A \_H O R} / 4 N_{\text {fault modes }}\right) \\
K_{f a, 3}=Q^{-1}\left(P_{F A \_V E R T} / 2 N_{\text {fault modes }}\right)
\end{gathered}
$$

$Q^{-1}(p)$ : it is the (1-p)-quantile of a zero-mean unitvariance Gaussian distribution

$P_{F A}$ : continuity budget allocated to disruptions due to false alert (distributed to the Vertical and Horizontals components).

The Protection Levels can be computed only if the following relation is valid for all $k$ and $q$ :

$$
\tau_{k, q}=\left|x_{q}^{(k)}-x_{q}^{(0)}\right| / T_{k, q} \leq 1
$$

If any of the tests fails, in the full version, the algorithm must attempt the exclusion of the fault.

- Computation of the Protection Levels (PL). Vertical Protection Level (VPL) and Horizontal Protection Levels (HPL) are the solutions of the following equations:

$$
\begin{aligned}
& 2 Q\left(\left(V P L-b_{3}^{(0)}\right) / \sigma^{(0)}{ }_{3}\right)+\Sigma_{k} p_{\text {fault }, k} Q\left(\left(V P L-T_{k, 3}-b^{(k)}{ }_{3}\right) / \sigma^{(0)}{ }_{3}\right) \\
&= P H M I_{V E R T}\left(1-\left(P_{\text {sat, not monitored }}+P_{\text {const,not_monitored }}\right)\right. \\
&\left./\left(P H M I_{V E R T}+P H M I_{H O R}\right)\right)
\end{aligned}
$$

$$
\begin{aligned}
2 Q\left(\left(H P L_{q}-b_{q}^{(0)}\right) / \sigma^{(0)}{ }_{q}\right)+\Sigma_{k} p_{f a u l t, k} Q\left(\left(H P L-T_{k, q}-b^{(k)}{ }_{q}\right) / \sigma^{(0)}{ }_{q}\right) \\
=1 / 2 P H M I_{H O R}\left(1-\left(P_{\text {sat, not monitored }}+P_{\text {const, not monitored }}\right)\right. \\
\left./\left(P H M I_{V E R T}+P H M I_{H O R}\right)\right)
\end{aligned}
$$

with $\mathrm{q}=1$ and 2 for $\mathrm{HPL}_{\mathrm{q}}$. The final HPL is given by:

$$
\mathrm{HPL}=\left(\mathrm{HPL}_{1}+\mathrm{HPL}_{2}\right)^{1 / 2}
$$

PHMI: total integrity budget, shared between the $H P L$ and VPL.

$P_{\text {sat/const not monitored }}$ removes from the PHMI budget the probability of the unmonitored fault modes.

$P_{\text {faul }, k}:$ prior probability of fault in satellite $k$ per approach

- Accuracy, Fault-free position error bound and effective monitor threshold. Finally, the other two parameters are computed: the accuracy and the Effective Monitoring Threshold.

$$
\begin{gathered}
\left.\sigma_{\mathrm{q}, \mathrm{acc}}=\left(e_{q}^{T} S^{(0)}\right) C_{a c c} S^{(0) T} e_{q}\right)^{1 / 2} \\
\mathrm{EMT}=\max _{\mathrm{k}}\left(\mathrm{T}_{\mathrm{k}, 3}\right)
\end{gathered}
$$

\section{B. The Matlab Algorithm Availability Simulation Tool (MAAST)}

MAAST is a set of Matlab functions developed by the University of Stanford for SBAS, RAIM and ARAIM availability analysis that is intended for use as a fast, accurate and highly customizable experimental testbed for algorithm development. The tool is open source and the original version and its related guides can be downloaded from the University of Stanford website [19]. The University of Stanford has also developed the ARAIM algorithm used in MAAST and it is based on the published papers [16].

The MAAST has the main objective of computing the four parameter indices of the reliability of the navigation solution provided by GNSS; these parameters are:

- The Horizontal Protection Level (HPL),

- The Vertical Protection Level (VPL),

- The Accuracy

- $\quad$ The Effective Monitoring Threshold (EMT).

The tool takes as input: 
- A map of the area of interest and density of the points to be analysed

- The YUMA Almanac files. These contain the orbital parameters for each satellite of the constellation (GPS/Galileo/GLONASS). GPS YUMA almanacs are downloaded from the CelesTrak website [20], which in turn are obtained from the US Coast Guard Navigation Center [21]. Galileo and GLONASS YUMA almanacs are provided with the MAAST and are based on the nominal constellation orbits.

- The Required Navigation Performance (RNP). In order to use GNSS as the primary source for navigation in aviation, stringent requirements have to be met, the so-called Required Navigation Performance (RNP) for civil aviation, a concept endorsed by the ICAO and explained in [22] and [23]. $\mathrm{RNP}$ is specified for the different flight phases in terms of the four parameters: accuracy, integrity, continuity of service and availability.

TABLE III

REQUiRed NAVIGATION PERFORMANCE [24]

\begin{tabular}{|c|c|c|c|c|c|}
\hline \multirow{3}{*}{ Operation } & \multirow{2}{*}{\multicolumn{2}{|c|}{$\begin{array}{l}\text { Accuracy } \\
95 \%(2 \sigma)\end{array}$}} & \multicolumn{3}{|c|}{ Integrity } \\
\hline & & & \multicolumn{2}{|c|}{ 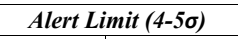 } & \multirow{2}{*}{$T T A$} \\
\hline & Vertical & Horizontal & Vertical & Horizontal & \\
\hline Oceanic & \multirow{4}{*}{ N/A } & \multirow{2}{*}{$\begin{array}{c}3.7 \mathrm{~km} \text { or } \\
\text { more }\end{array}$} & \multirow{4}{*}{ N/A } & \multirow{2}{*}{$\begin{array}{l}7.4 \mathrm{~km} \text { or } \\
\text { more }\end{array}$} & \multirow{2}{*}{$1-5 \mathrm{~min}$} \\
\hline En-route & & & & & \\
\hline Terminal & & \multirow{2}{*}{$\begin{array}{c}0.22-0.74 \\
\mathrm{~km}\end{array}$} & & \multirow{2}{*}{$\begin{array}{c}1.85-3.7 \\
\mathrm{~km}\end{array}$} & \multirow{2}{*}{$10-15 \mathrm{~s}$} \\
\hline NPA & & & & & \\
\hline LNAV/VNAV & \multirow{3}{*}{$20 \mathrm{~m}$} & $220 \mathrm{~m}$ & \multirow{2}{*}{$50 \mathrm{~m}$} & $556 \mathrm{~m}$ & \multirow{3}{*}{$10 \mathrm{~s}$} \\
\hline LPV & & \multirow{5}{*}{$16 \mathrm{~m}$} & & \multirow{5}{*}{$40 \mathrm{~m}$} & \\
\hline APV I & & & $35 \mathrm{~m}$ & & \\
\hline APV II & $8 \mathrm{~m}$ & & $20 \mathrm{~m}$ & & \multirow{3}{*}{$6 s$} \\
\hline LPV-200 & \multirow{2}{*}{$4 \mathrm{~m}$} & & $35 \mathrm{~m}$ & & \\
\hline CAT I & & & $10 \mathrm{~m}$ & & \\
\hline CAT II & \multirow{2}{*}{$<2.0 \mathrm{~m}$} & \multirow{2}{*}{$<6.9 \mathrm{~m}$} & \multirow{2}{*}{$5.3 \mathrm{~m}$} & \multirow{2}{*}{$<15.5 \mathrm{~m}$} & \multirow{2}{*}{$<2 \mathrm{~s}$} \\
\hline CAT III & & & & & \\
\hline
\end{tabular}

\begin{tabular}{|c|c|c|c|}
\hline \multirow[b]{2}{*}{ Operation } & \multicolumn{2}{|c|}{ Max Probabilities of Failure } & \multirow[b]{2}{*}{ Availability } \\
\hline & $\begin{array}{c}\text { Integrity } \\
\text { (1-risk) }\end{array}$ & $\begin{array}{c}\text { Continuity } \\
\text { (1-risk) }\end{array}$ & \\
\hline Oceanic, En-route & \multirow{2}{*}{$10^{-7} / \mathrm{hr}$} & \multirow{2}{*}{$10^{-4} / \mathrm{hr}$} & \multirow{10}{*}{$10^{-2}$ to $10^{-5}$} \\
\hline Terminal, NPA & & & \\
\hline LNAV/VNAV & \multirow{6}{*}{$\begin{array}{c}1.2 \times 10^{-7} / \\
150 \mathrm{~s}\end{array}$} & \multirow{6}{*}{$\begin{array}{c}4.8 \times 10^{-6} / \\
15 \mathrm{~s}\end{array}$} & \\
\hline LPV & & & \\
\hline APV I & & & \\
\hline APV II & & & \\
\hline LPV-200 & & & \\
\hline CAT I & & & \\
\hline CAT II & \multirow{2}{*}{$\begin{array}{l}<10^{-9} / \\
150 \mathrm{~s}\end{array}$} & \multirow{2}{*}{$\begin{array}{c}<4 \times 10^{-6} / \\
15 \mathrm{~s}\end{array}$} & \\
\hline CAT III & & & \\
\hline
\end{tabular}

- Signal errors and biases characterisation. They can be specified for each satellite of the different constellation and expressed in terms of:

- User Range Error (URE) and Signal-in-Space-Error for Galileo (SISE).

- User-Range-Accuracy (URA) and Signal-in-spaceaccuracy, for Galileo (SISA).

- Two levels of bias magnitudes for the range measurements: one is the magnitude of a bias in a nominal condition $\left(b_{\text {nom }}\right)$, used for the evaluation of accuracy and continuity, the other is the maximum bias magnitude used or the evaluation of integrity $\left(b_{\text {int }}\right)$.

- Probability of failure for each satellite and constellation $\left(\mathrm{P}_{\text {sat }}\right.$ and $\left.\mathrm{P}_{\text {const }}\right)$.

\section{THE ARAIM PERFORMANCE ON PREDICTED AIRCRAFT TRAJECTORY TOOL (APPATT)}

For the purpose of this research, MAAST has been selected and modified in order to analyse the ARAIM performance along aircraft trajectories considering the shadowing effect of the aircraft attitude and surrounding environments.

The newly developed algorithm, named APPATT, has the same objective as MAAST, to compute the four parameters indices of the reliability of the navigation solution provided by GNSS but with two main differences:

- The tool computes the parameters both while considering and not considering the shadowing effects, in order to evaluate the difference

- $\quad$ The parameters are predicted for a specific point and time; they are not averaged values, but instantaneous, only valid for that well-defined configuration of the satellites constellations and signal errors and bias characterisation.

\section{A. Input and Output}

The new tool takes as additional input:

- The aircraft trajectory file. This is a text file generated by the RNAV Validation Tool (RVT) software developed by the DW International Ltd. The trajectory is defined in terms of waypoints and the file provides information for each point related to the position, attitude and performance of the aircraft, such as:

- $\quad$ Latitude, Longitude and Altitude

- $\quad$ Bank and Heading angles

- $\quad$ Time (in seconds since trajectory started)

- Calibrated and True Airspeed (CAS and TAS), Vertical Speed (VS) and Acceleration

- Fuel Consumption and Thrust (based on the performance of the selected aircraft used for the simulation) 
- $\quad$ Flight starting time, expressed in days, hours, minutes and seconds since the beginning of the week (the YUMA almanacs are provided weekly)

- The high-resolution topographic data generated from NASA's Space Shuttle Radar Topography Mission (SRTM) [25]. The elevation models are arranged into tiles, each covering one degree of latitude and one degree of longitude. The resolution of the raw data is one arc second $(30 \mathrm{~m})$, over United States territory. For the rest of the world, only three arc second $(90 \mathrm{~m})$ data are available. Each one arcsecond tile has 3,601 rows, each consisting of 3,601 16 bit big-endian cells. The dimensions of the three arc second tiles are $1201 \times 1201$ cells. The original SRTM elevations were calculated relative to the WGS84 ellipsoid and then the EGM96 geoid separation values were added to convert to heights relative to the geoid for all the released products.

The tool provides as output for each trajectory waypoint:

- Predicted ARAIM Performance with respect to the East North Up (ENU) reference frame (no shadow effect included, full view of the sky)

- Predicted ARAIM Performance with respect to the aircraft body reference frame (both attitude and environment shadowing effect included)

- Number of satellites in view in the two reference systems

- Number of satellites lost due to the shadowing effects

Fig. 5 resumes the flow chart and functions of the APPATT algorithm.

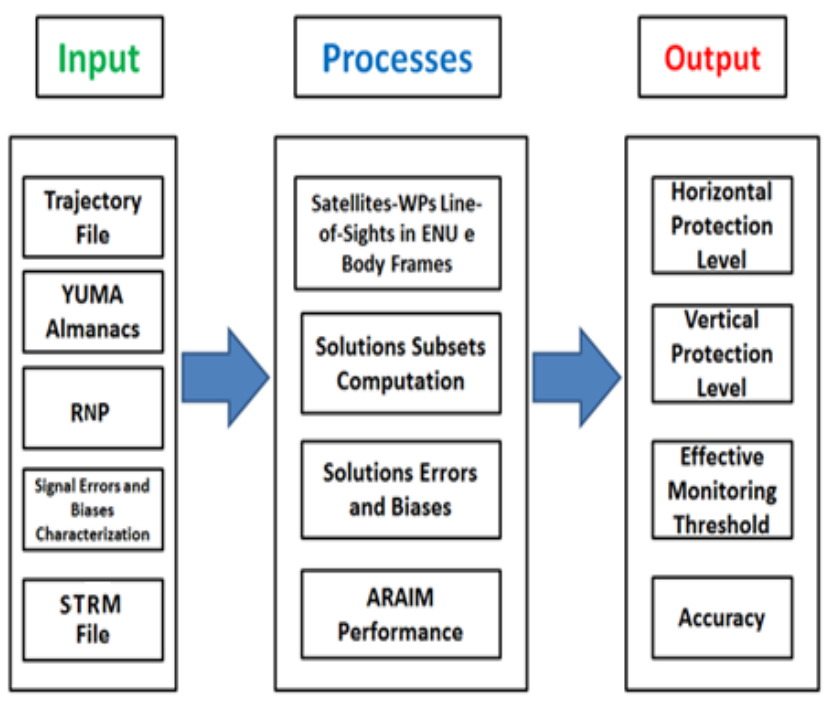

Fig. 5. APPATT Scheme

\section{B. Computation of the shadowing effect of the aircraft attitude}

RVT is a desktop application, developed by DW International Ltd for EUROCONTROL, to help procedure designers in the ground validation of new or modified Radio Navigation (RNAV) Standard Instrument Departures (SIDs) and Standard Terminal Arrival Routes (STAR). Ground validation is a key step between the design and the implementation of RNAV procedures.

One of the RVT software features is the simulation of the aircraft dynamics along the defined trajectory. After each simulation, the software generates an output file with information related to position, attitude, velocity and aircraft performance. The trajectory parameters are recorded every 5 seconds in level flight, while the time step reduces during maneuvers. The APPATT includes a function that linearly interpolates the data in order to have a user defined time step (e.g. 1 second, like the update frequency of GNSS position estimation). The main limitation of the RVT output file is that, regarding the aircraft attitude, it only provides the bank and heading angles; for this reason we have considered the following hypothesis:

- $\quad$ Bank angle $=$ Roll angle

- $\quad$ Heading angle $=$ Yaw angle

- $\quad$ Ramp angle $=$ Pitch angle

The first and second hypotheses are valid if there is "no wind" or trim condition during the flight. The third is a worst case approximation, since the RVT software doesn't provide the ramp angle. In the APPATT, the ramp angle is taken as equal to the angle between the aircraft local horizon and the trajectory between two waypoints (not always true since the altitude of the airplane can change even if the pitch angle is null or it can be constant even if the pitch angle is not zero).

The APPATT algorithm uses the waypoints coordinates, the time information and the orbital elements provided by the YUMA almanacs to compute the aircraft and satellites' positions respect to the Earth Centered Earth Fixed (ECEF) reference system. Afterwards, it computes the Line-of-Sight (LoS) unit vectors between each aircraft position and all the satellites of the considered constellations. Then the LoS unit vectors are computed in the local East, North and Up (ENU) reference frame for each location and the satellites below the horizon (with the $\mathrm{z}$ component of the LoS being negative) are removed from the computation (Figure 6). In order to evaluate the effect of the attitude of the aircraft, the LoS are assessed in the NED (North-East-Down) and Body reference frame (Roll, Pitch and Yaw axes) (Fig. 7). NED coordinates to describe observations made from an aircraft are normally given relative to its intrinsic axes, but normally using as positive the coordinate pointing downwards, where the interesting points are located. At each change of reference frame, the algorithm computes and uses the corresponding rotation matrix to transform the LoS unit vectors. 


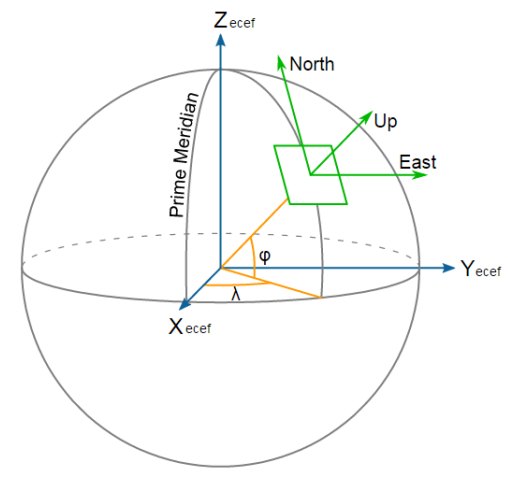

Fig. 6. ECEF and ENU reference frames [26]

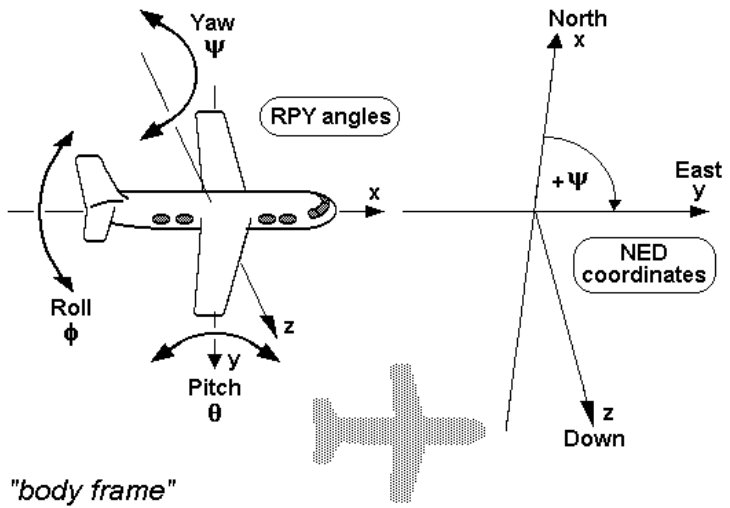

Fig. 7. NED and Body Reference Frames [26]

Fig. 8 shows an example of the result of a specific point of the trajectory of an aircraft with banking angle of 20 degrees; there are three different reference systems, blue is the ENU, yellow the NED and magenta is the Body reference system. The red dots are the satellite in view in the ENU reference system, while the green circle is the aircraft horizontal plane ( $\mathrm{x}-\mathrm{y}$ or roll-pitch plane) and on the right side of the picture it is easy to see that there are three satellites below the GNSS receiver's field of view, reducing the number of satellites in view and affecting the ARAIM performance as will be shown in the following sections.

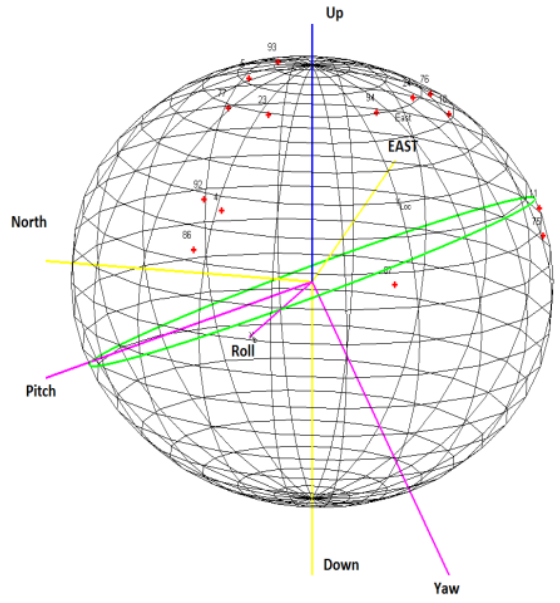

Fig. 8. Example of shadowing effect due to the aircraft attitude

\section{Computation of the shadowing effect of the surrounding environment}

The APPATT reads and loads the SRTM data, provided as input, which covers the terrain surrounding the trajectory within a certain distance. Then the data passes through a series of filters and checks in order reduce the computational load (each SRTM file contains around 1.4 million sample points). Fig. 9 shows an example of a horizon mask, a 2D representation of the local sky view; the circle center is the local zenith and each circle is the elevation angle with respect to the local horizon represented by the external circumference. The spokes are the directions (also defined as azimuth or heading angles) with respect to the North direction. The red line and dots are the local terrain profile that could shadow one or more satellites. The main objective of this function is to find the satellites that are shadowed by the terrain.

The following list shows some of the checks that the algorithm performs:

- Remove all of the points with altitude lower than the aircraft.

- Compute the LoS of the points left with the aircraft positions and compute their elevation and heading angles with respect to the NED reference system.

- Remove from the computation the satellites with elevation angles higher than the highest elevation angle of the sample points (it reduces the number of satellites to check)

- Find the pair of points that have the closest heading angles for each satellite (one point higher the other lower).

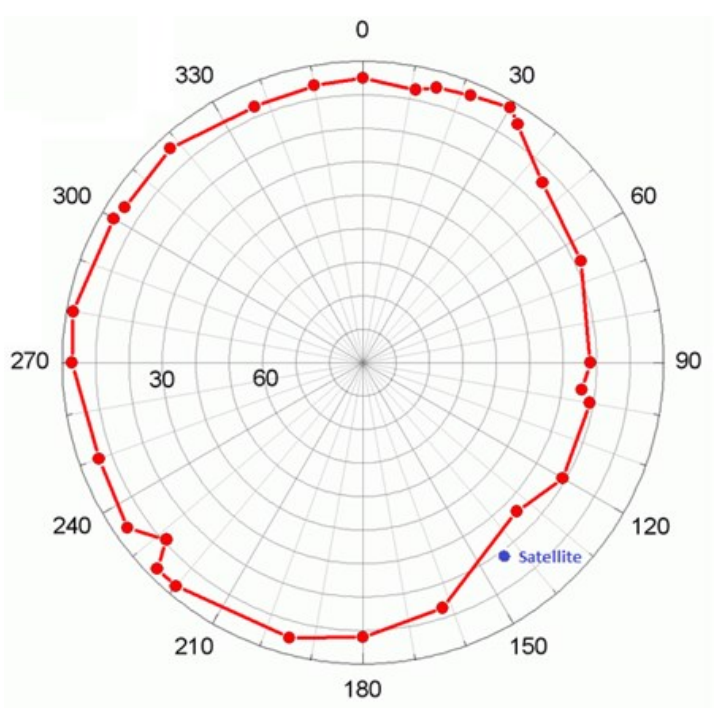

Fig. 9. Example of horizon mask with satellite in shadow 
- Linearly interpolate the elevation angle of the pairs of points in order to find the elevation of the points that have the same heading angles of the satellites and compare the elevation angles.

- Determine if the satellite is shadowed (satellite elevation lower than the computed point)

\section{SCENARIOS AND RESULTS}

\section{A. Scenarios}

Three different approach procedures have been selected for the ARAIM prediction analysis:

- Fairbanks (Alaska) (Fig. 11) and Cairns (Australia) (Fig. 12) due to their positions in areas of low ARAIM performance according to the analysis computed by the University of Stanford using a single constellation configuration (Fig. 10).

- Innsbruck (Austria) (Fig. 13) due to its particular location, where the environment shadowing effect could increase the number of the satellites not available.

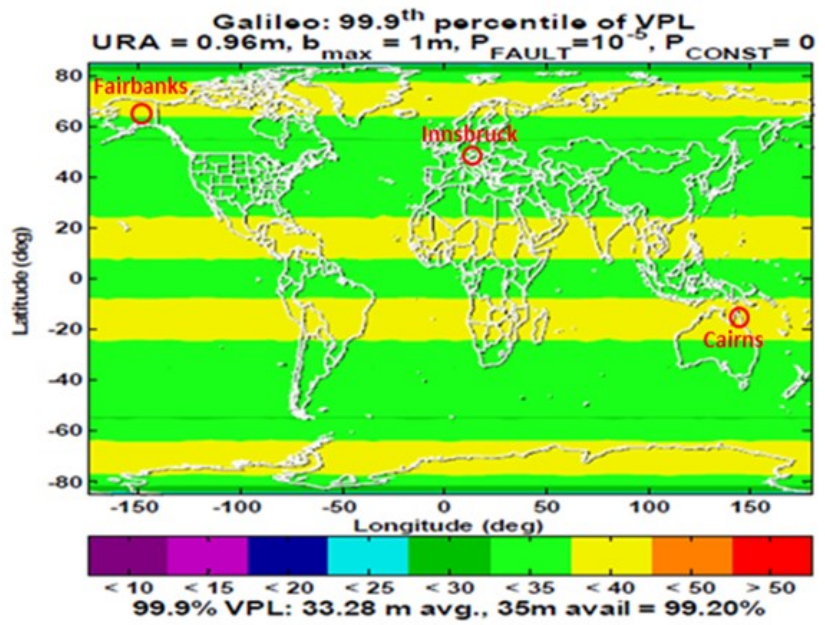

Fig. 10. Selected Airport Locations

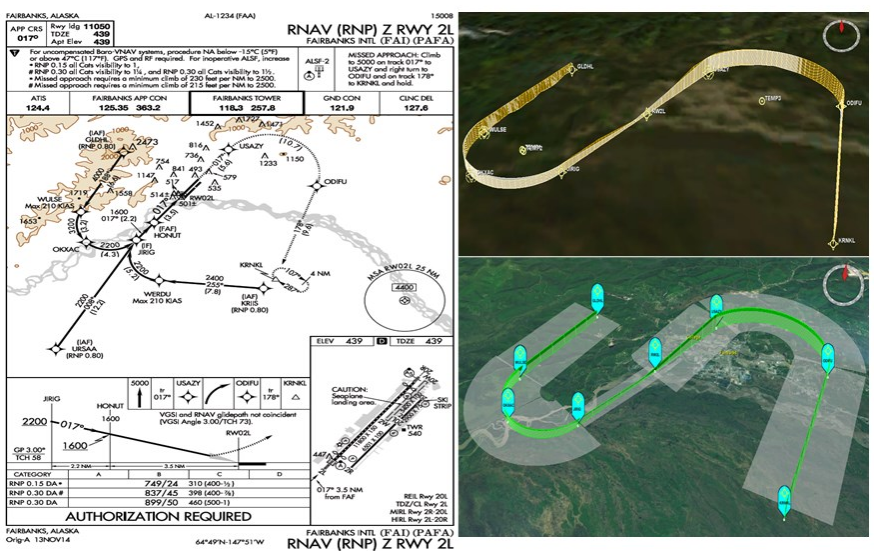

Fig. 11. Fairbanks Approach Procedure

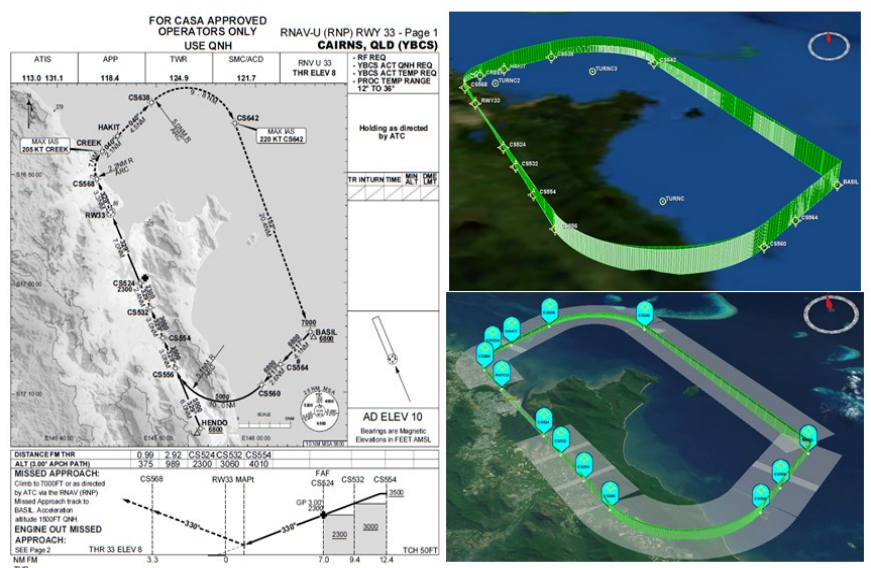

Fig. 12. Cairns Approach Procedure

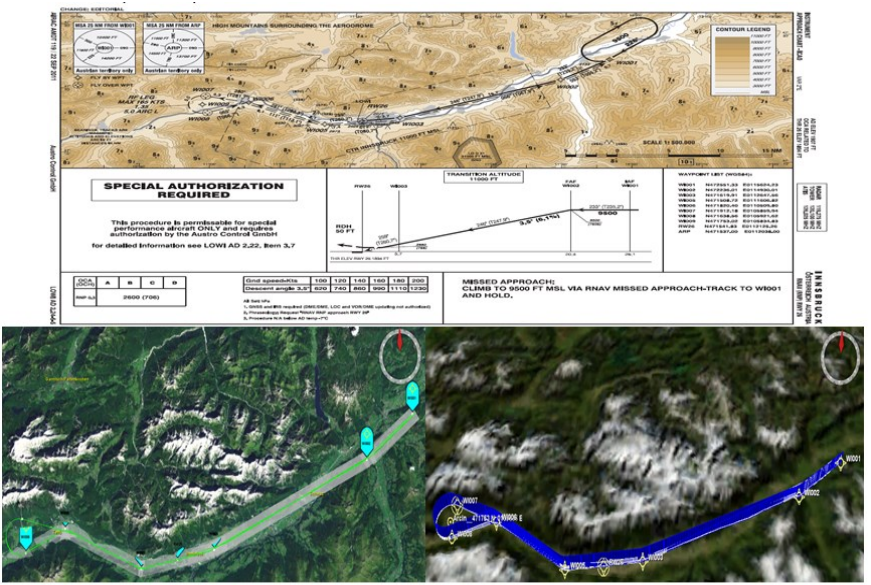

Fig. 13. Innsbruck Approach Procedure

The other main advantage of these three approaches is that they include a wide variety of maneuvers $(90,180$ and 270 degrees maneuvers).

\section{B. Results}

The three trajectories have been analysed in different scenarios (single, dual and tri-constellation), combining the different constellations: GPS, Galileo (24 and 27 satellites nominal configuration) and GLONASS (23 satellites nominal configuration). The tool provides as output several graphs:

- Aircraft attitude along the trajectory: Roll, Pitch and Yaw angles.

- Number of satellites in view in the ENU (red line) and Body (blue line) reference system, in order to highlight the difference.

- Horizontal and Vertical Protection Level (HPL and VPL), Accuracy and Effective Monitoring Threshold in the ENU (green line) and Body reference frame (blue line) respect to the Alert Limit (red line).

Table IV summarises the values used by Stanford University for the parameters, used as reference for the trajectory analysis: 
TABLE IV.

PARAMETER DEFINITIONS

\begin{tabular}{|c|c|c|}
\hline Name & Description & Value \\
\hline$\sigma_{\mathrm{URA}, i}$ & $\begin{array}{l}\text { standard deviation of the clock and } \\
\text { ephemeris error of satellite } i \text { used for } \\
\text { integrity }\end{array}$ & $1 \mathrm{~m}$ \\
\hline$\sigma_{\mathrm{URE}, i}$ & $\begin{array}{l}\text { standard deviation of the clock and } \\
\text { ephemeris error of satellite } i \text { used for } \\
\text { accuracy and continuity }\end{array}$ & $0.5 \mathrm{~m}$ \\
\hline Bias_cont & $\begin{array}{c}\text { Tropospheric delay of satellite } i \text {, function of } \\
\text { its elevation angle }\end{array}$ & $0 \mathrm{~m}$ \\
\hline Bias_int & $\begin{array}{l}\text { Maximum nominal bias for satellite i, used } \\
\text { for integrity }\end{array}$ & $0.75 \mathrm{~m}$ \\
\hline $\mathrm{P}_{\text {sat }}$ & $\begin{array}{l}\text { Probability of satellite failure of the single } \\
\text { satellite }\end{array}$ & $10^{-5}$ \\
\hline $\mathrm{P}_{\text {const }}$ & Probability of constellation failure & $10^{-4}$ \\
\hline PHMI & Total integrity budget & $10^{-7}$ \\
\hline PHMI $_{\text {VERT }}$ & Integrity budget for the vertical component & $\underset{8}{9.8 \times 10^{-}}$ \\
\hline $\mathrm{PHMI}_{\mathrm{HOR}}$ & $\begin{array}{l}\text { Integrity budget for the horizontal } \\
\text { component }\end{array}$ & $2 \times 10^{-9}$ \\
\hline $\mathrm{P}_{\mathrm{FA}}$ & $\begin{array}{l}\text { Continuity budget allocated to disruptions } \\
\text { due to false alert. The total continuity } \\
\text { budget is } 8 \times 10^{-6} \text { per approach. }\end{array}$ & $4 \times 10^{-6}$ \\
\hline $\mathrm{P}_{\mathrm{FA} \_ \text {VERT }}$ & $\begin{array}{l}\text { Continuity budget allocated to the vertical } \\
\text { mode }\end{array}$ & $3.9 \times 10^{-}$ \\
\hline $\mathrm{P}_{\mathrm{FA} \_ \text {HOR }}$ & $\begin{array}{l}\text { Continuity budget allocated to the } \\
\text { horizontal mode }\end{array}$ & $9 \times 10^{-8}$ \\
\hline $\mathrm{P}_{\mathrm{EMT}}$ & $\begin{array}{l}\text { Probability used for the calculation of the } \\
\text { Effective Monitor Threshold }\end{array}$ & $10^{-5}$ \\
\hline
\end{tabular}

- Scenario: GPS.

\section{- Cairns}

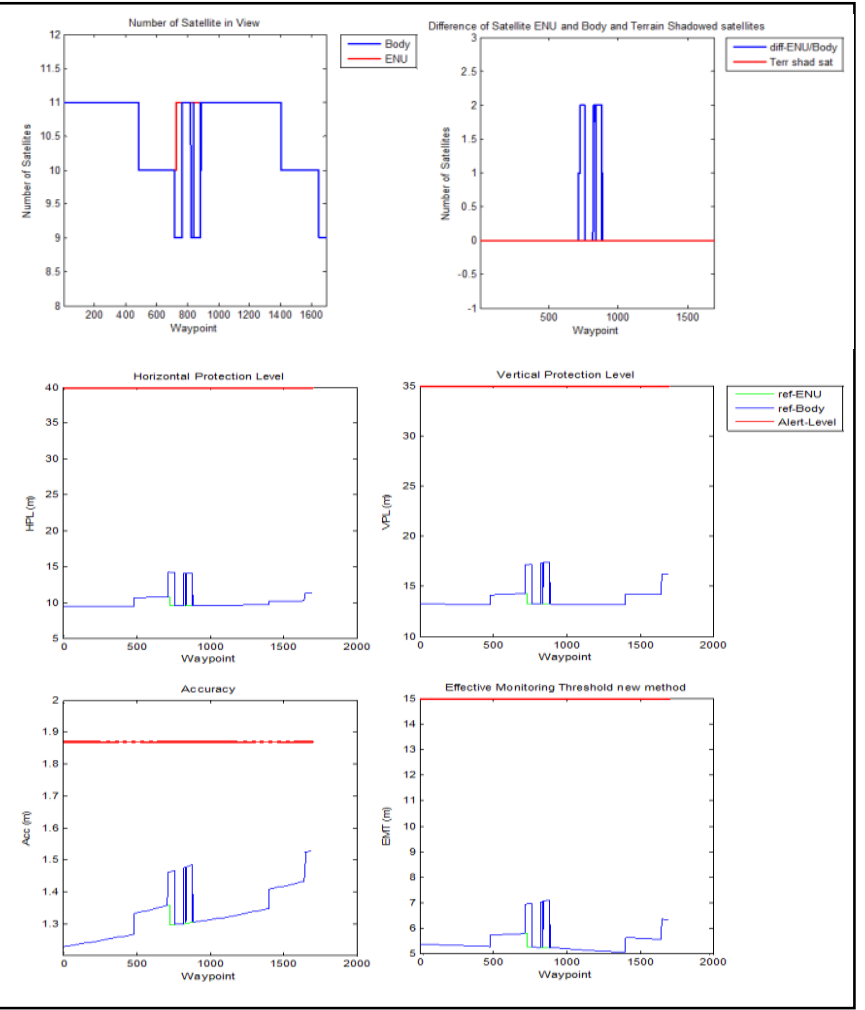

- $\quad$ Fairbanks

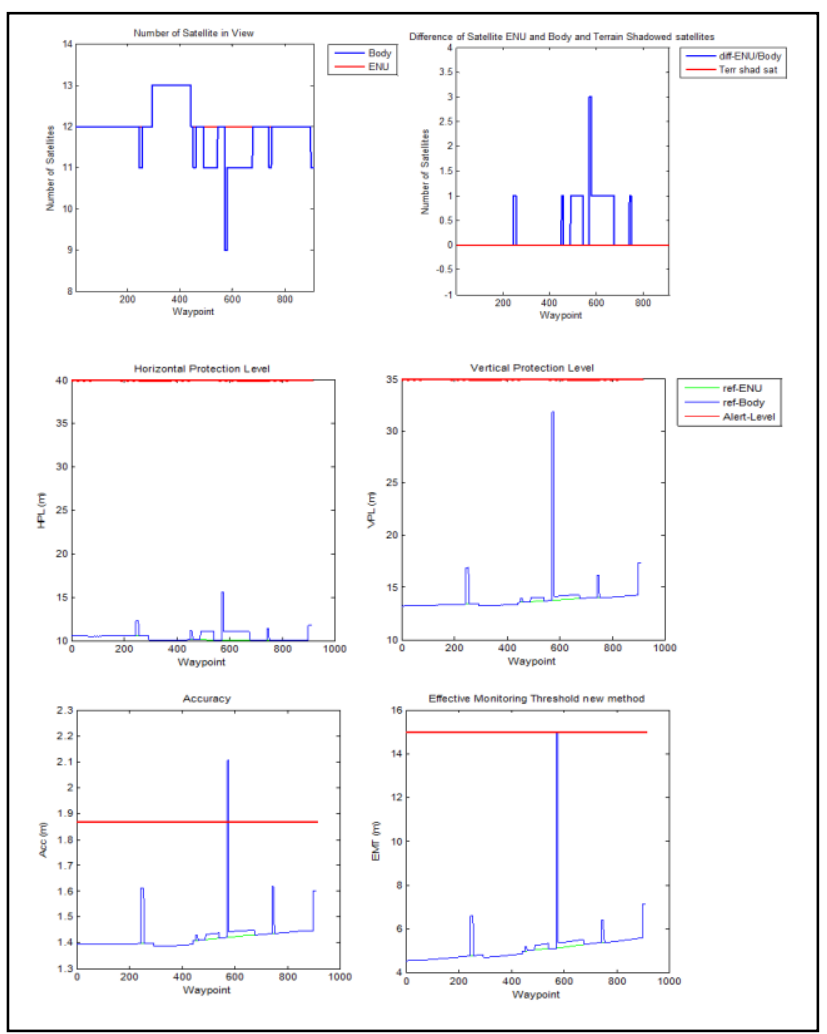

- Innsbruck

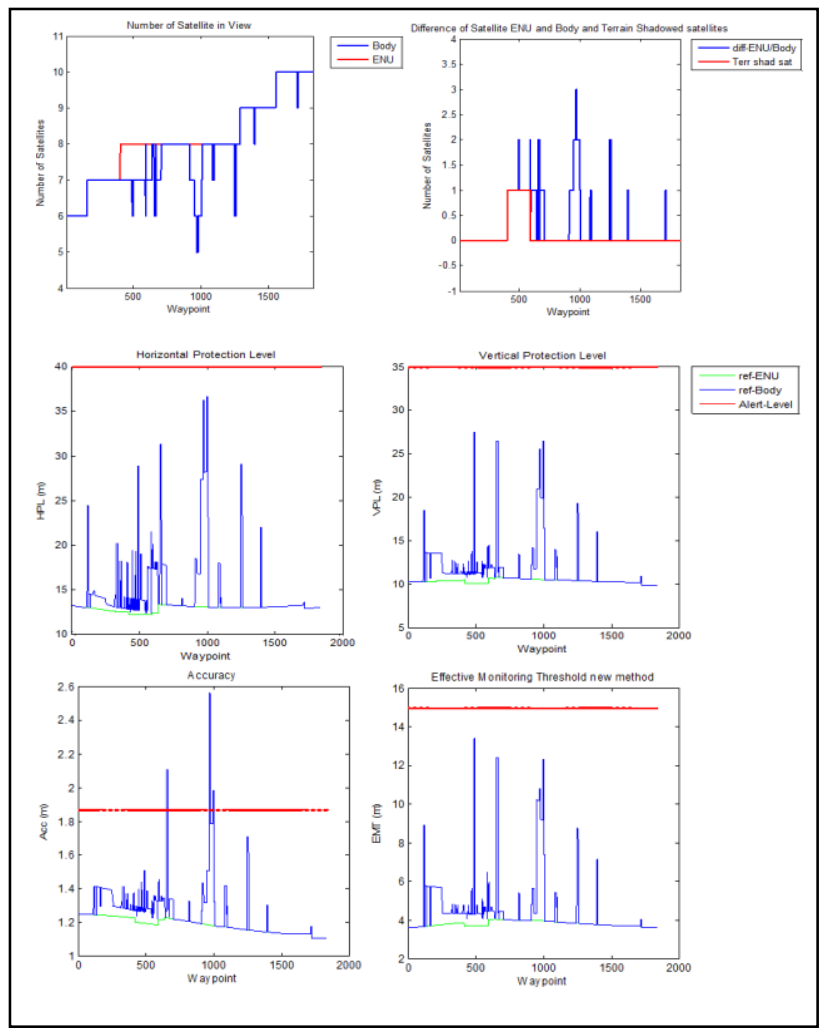


It is easy to see that each satellite lost generates an increase of the values of the parameters. In particular, for the Fairbanks and Innsbruck approaches, some of the parameters reach or exceed the alert limits. Table IV shows the maximum values of the parameter, in the body reference frame, for the three approaches and compares them with the corresponding value in the ENU frame and the alert limit (red values exceed the AL, orange are close to the AL but with less than $20 \%$ margin)

TABLE V. PERFORMANCE COMPARISON FOR THE GPS CONFIGURATION

\begin{tabular}{|c|c|c|c|c|c|c|}
\hline Param. & Location & $\begin{array}{c}\text { Max } \\
\text { Body Ref }\end{array}$ & $\begin{array}{l}\text { ENU } \\
\text { value }\end{array}$ & $\begin{array}{c}\Delta B o d y \\
- \\
\text { ENU\% }\end{array}$ & $\triangle A L \%$ & $A L$ \\
\hline \multirow{3}{*}{ HPL (m) } & Cairns & 14.2 & 10.8 & 31.8 & -64.4 & \multirow{3}{*}{40} \\
\hline & Fairbanks & 15.6 & 10.1 & 54.5 & -61.1 & \\
\hline & Innsbruck & 84.7 & 14.0 & 503.8 & 111.7 & \\
\hline \multirow{3}{*}{ VPL (m) } & Cairns & 17.4 & 13.2 & 31.9 & -50.2 & \multirow{3}{*}{35} \\
\hline & Fairbanks & 31.84 & 13.8 & 131.4 & -9.0 & \\
\hline & Innsbruck & 84.9 & 13.2 & 541.2 & 142.6 & \\
\hline \multirow{3}{*}{$\mathrm{EMT}(\mathrm{m})$} & Cairns & 7.1 & 5.2 & 35.7 & -52.7 & \multirow{3}{*}{15} \\
\hline & Fairbanks & 14.97 & 5.1 & 191.7 & -0.2 & \\
\hline & Innsbruck & 42.0 & 5.3 & 697.3 & 179.7 & \\
\hline \multirow{3}{*}{$\operatorname{Acc}(m)$} & Cairns & 1.53 & 1.5 & 0.02 & -18.3 & \multirow{3}{*}{1.87} \\
\hline & Fairbanks & 2.11 & 1.4 & 48.2 & 12.6 & \\
\hline & Innsbruck & 3.3 & 1.3 & 153.0 & 76.4 & \\
\hline
\end{tabular}

In this scenario, Innsbruck and Fairbanks approaches do not satisfy the LPV-200 requirements, while Cairns does but with a warning in the accuracy parameter.

- $\quad$ Scenario: GPS + Galileo 24 Space Vehicle (SV)

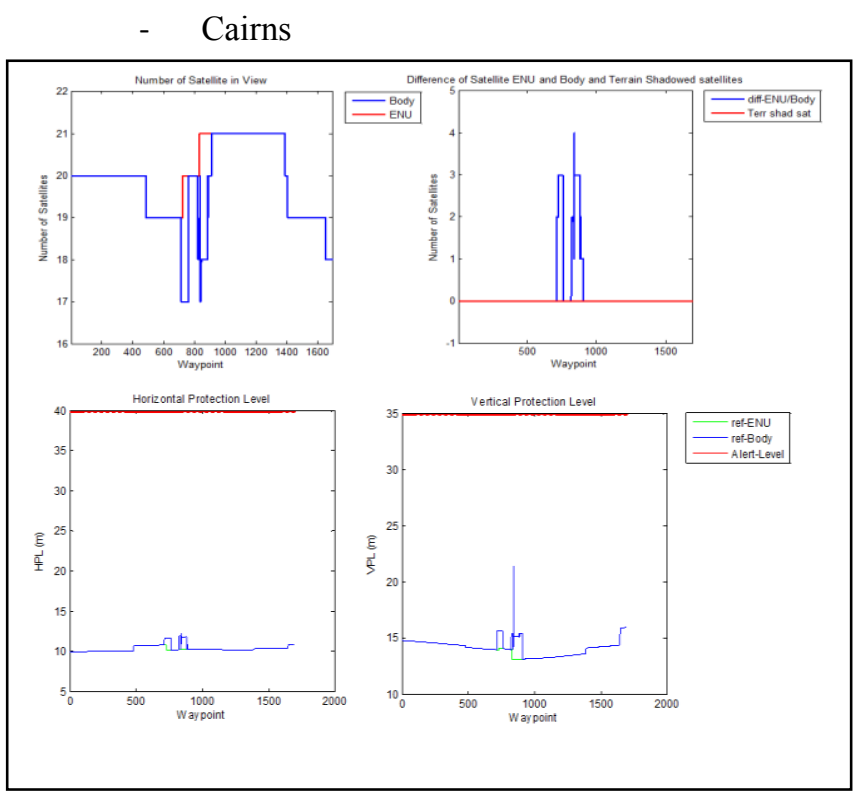

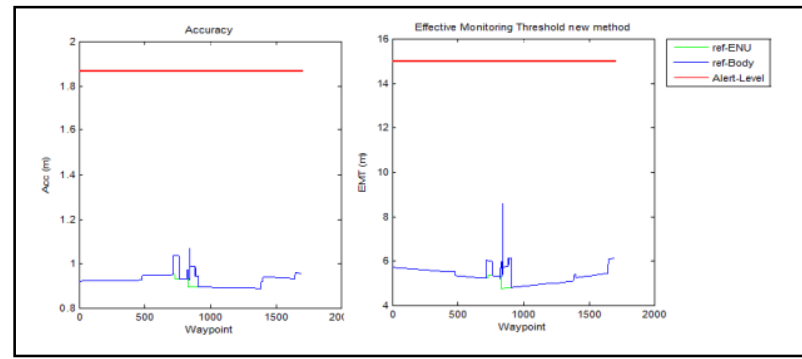

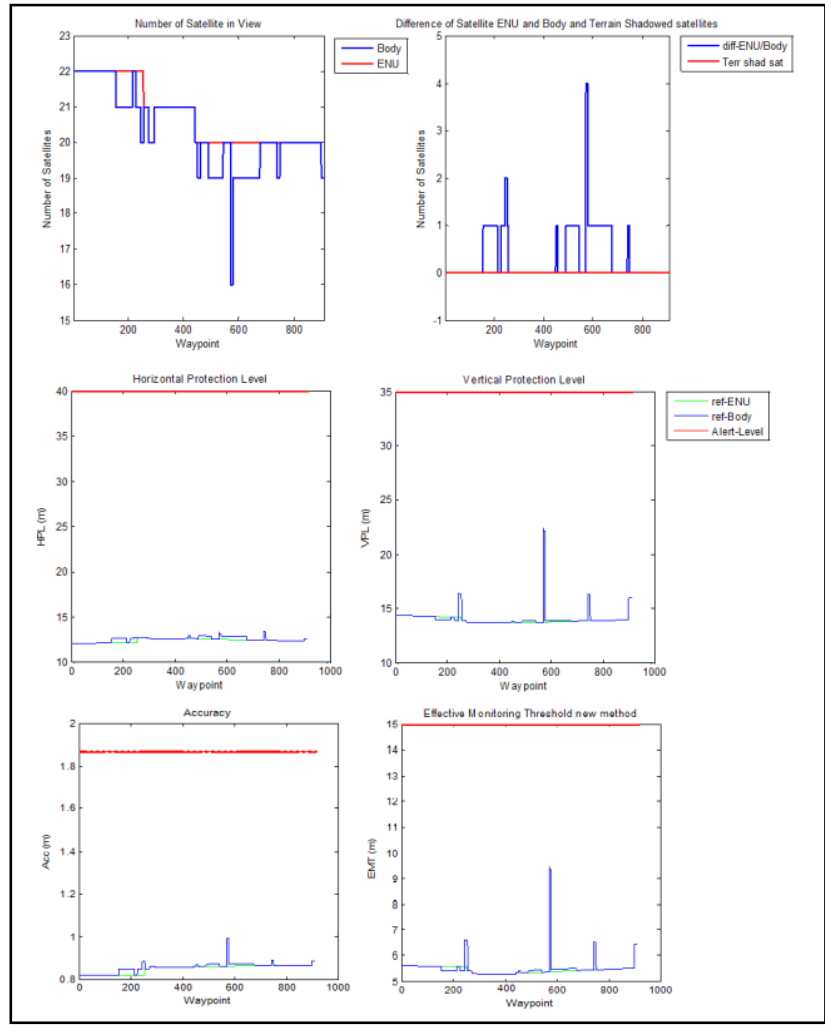

- Fairbanks

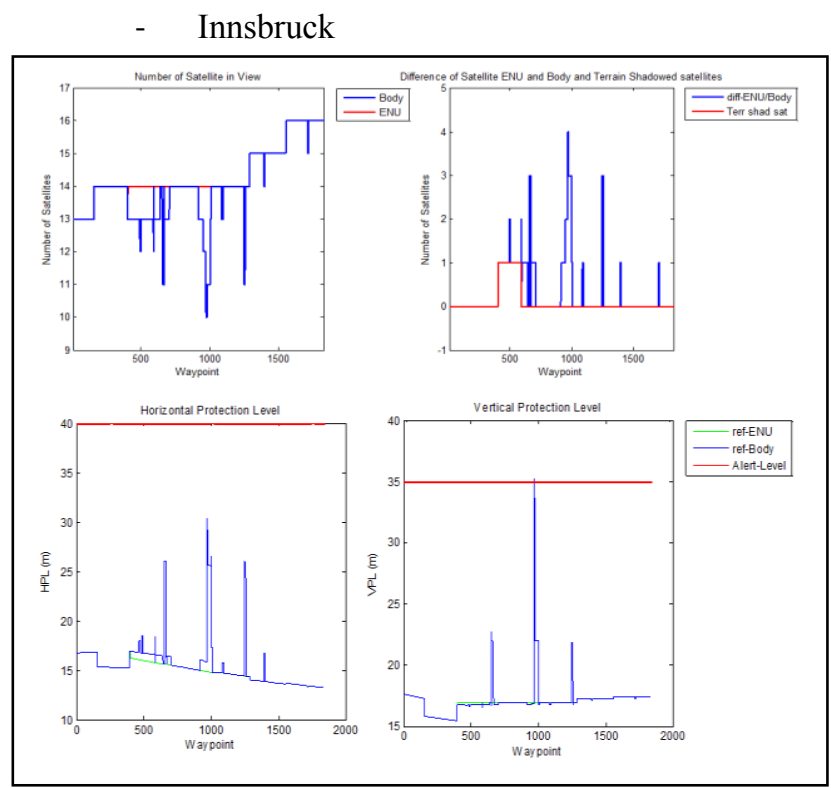




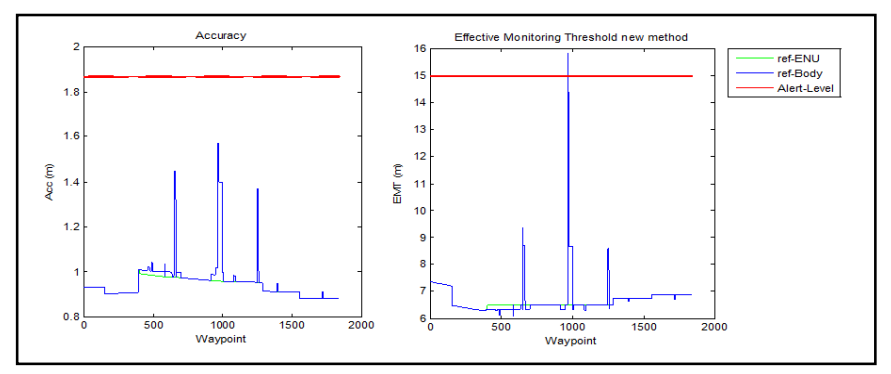

TABLE VI

PERFORMANCE COMPARISON FOR THE GPS + GALILEO 24SV CONFIGURATION

\begin{tabular}{|c|c|c|c|c|c|c|}
\hline Param. & Location & $\begin{array}{c}\text { Max } \\
\text { Body Ref }\end{array}$ & $\begin{array}{l}\text { ENU } \\
\text { value }\end{array}$ & $\begin{array}{c}\text { BBody } \\
- \\
\text { ENU\% }\end{array}$ & $\triangle A L \%$ & $A L$ \\
\hline \multirow{3}{*}{ HPL (m) } & Cairns & 12.3 & 10.3 & 19.3 & -69.3 & \multirow{3}{*}{40} \\
\hline & Fairbanks & 13.4 & 12.5 & 7.5 & -66.4 & \\
\hline & Innsbruck & 30.5 & 14.3 & 113.6 & -23.8 & \\
\hline \multirow{3}{*}{ VPL (m) } & Cairns & 21.4 & 13.1 & 63.2 & -38.8 & \multirow{3}{*}{35} \\
\hline & Fairbanks & 22.4 & 13.8 & 62.4 & -36.0 & \\
\hline & Innsbruck & 35.4 & 16.6 & 113.1 & 1.0 & \\
\hline \multirow{3}{*}{ EMT (m) } & Cairns & 8.6 & 4.8 & 79.7 & -42.9 & \multirow{3}{*}{15} \\
\hline & Fairbanks & 9.5 & 5.4 & 76.5 & -37.0 & \\
\hline & Innsbruck & 15.9 & 6.2 & 156.3 & 6.0 & \\
\hline \multirow{3}{*}{$\operatorname{Acc}(m)$} & Cairns & 1.1 & 0.9 & 19.6 & -42.8 & \multirow{3}{*}{1.87} \\
\hline & Fairbanks & 1.0 & 0.9 & 15.0 & -46.9 & \\
\hline & Innsbruck & 1.56 & 1.0 & 153.0 & -16.4 & \\
\hline
\end{tabular}

The addition of a second constellation considerably improved the performance. Both Cairns and Fairbanks satisfy LPV-200 requirements, while Innsbruck has only two parameters below the thresholds.

- Scenario: GPS + Galileo 24 SV + GLONASS

\section{- Cairns}

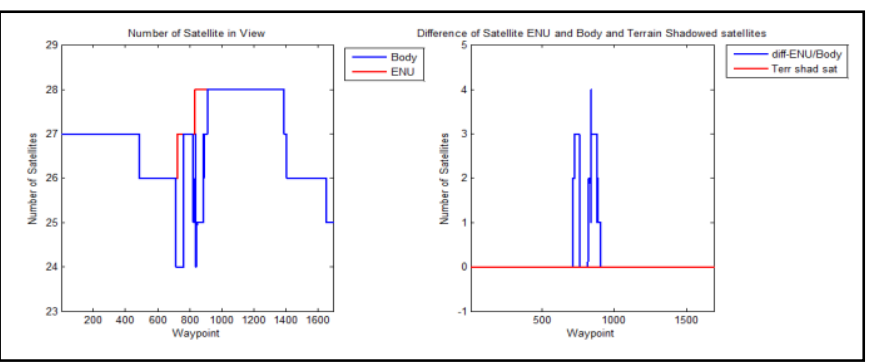

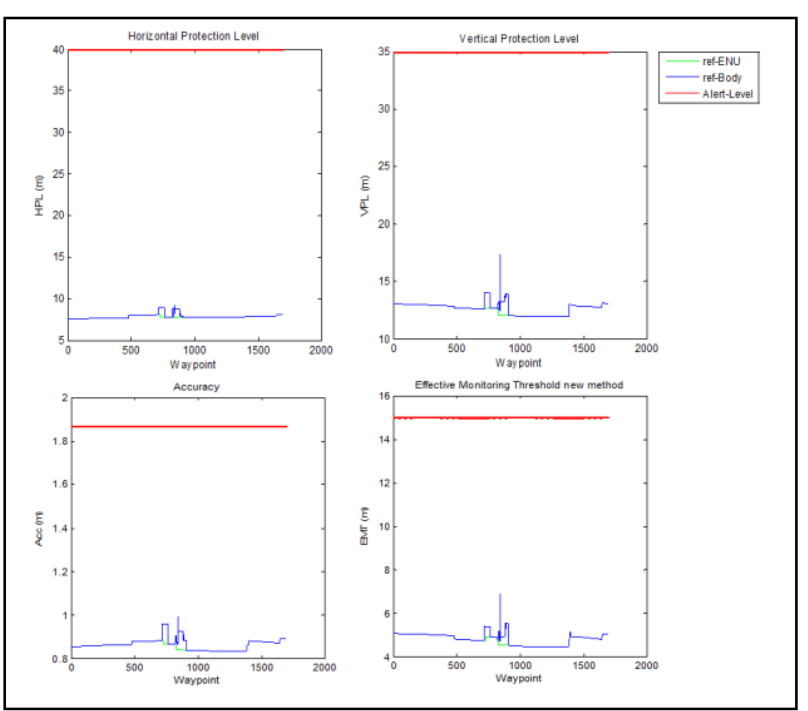

- Fairbanks

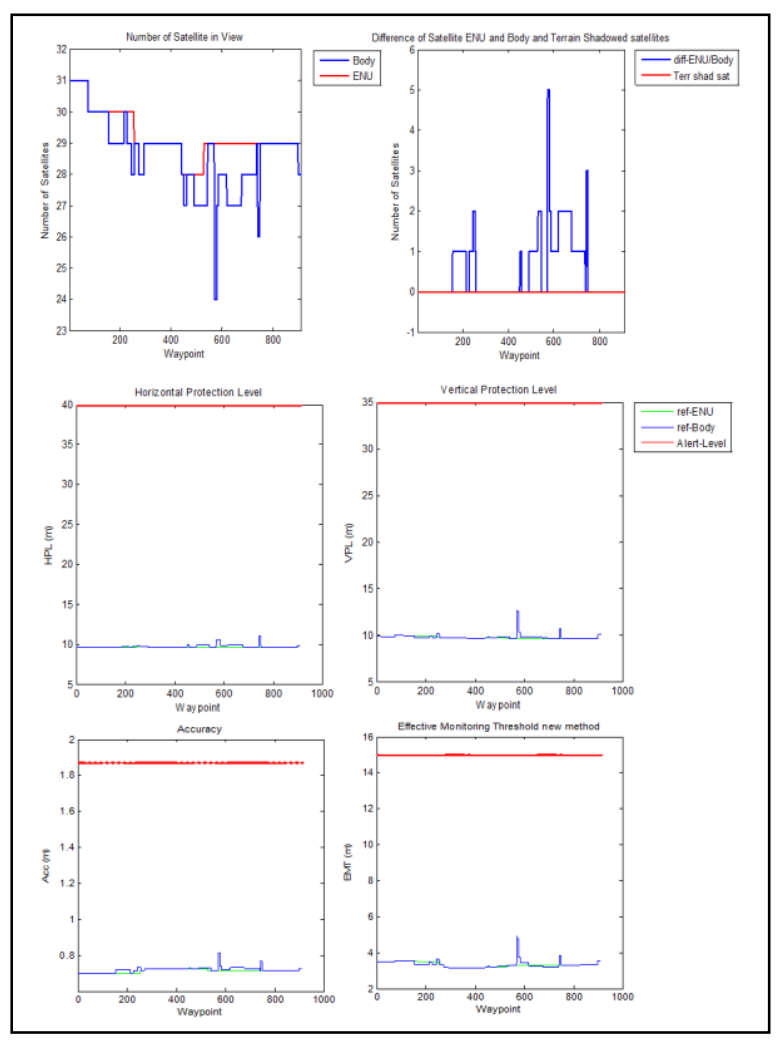


- $\quad$ Innsbruck

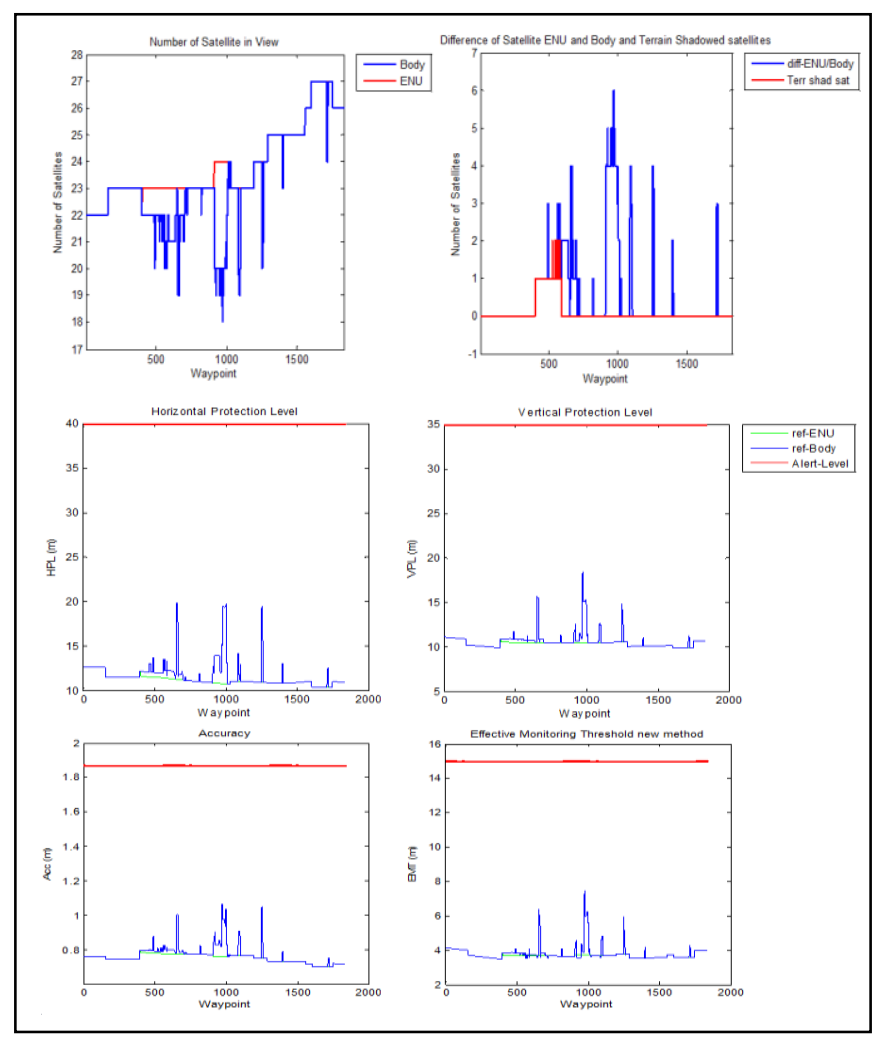

TABLE VII. PERFORMANCE COMPARISON FOR THE GPS + GALILEO 24SV + GLONASS CONFIGURATION

\begin{tabular}{|c|c|c|c|c|c|c|}
\hline Param. & Location & $\begin{array}{c}\text { Max } \\
\text { Body Ref }\end{array}$ & $\begin{array}{l}\text { ENU } \\
\text { value }\end{array}$ & $\begin{array}{c}\Delta B o d y \\
- \\
\text { ENU\% }\end{array}$ & $\triangle A L \%$ & $A L$ \\
\hline \multirow{3}{*}{ HPL (m) } & Cairns & 9.2 & 7.7 & 19.5 & -77.0 & \multirow{3}{*}{40} \\
\hline & Fairbanks & 11.1 & 9.7 & 15.1 & -72.2 & \\
\hline & Innsbruck & 20.0 & 11.7 & 71.3 & -50.0 & \\
\hline \multirow{3}{*}{$\operatorname{VPL}(\mathrm{m})$} & Cairns & 17.3 & 12.0 & 44.3 & -50.5 & \multirow{3}{*}{35} \\
\hline & Fairbanks & 12.5 & 9.7 & 29.6 & -64.3 & \\
\hline & Innsbruck & 18.4 & 10.5 & 74.9 & -47.6 & \\
\hline \multirow{3}{*}{ EMT (m) } & Cairns & 6.9 & 4.5 & 51.6 & -54.0 & \multirow{3}{*}{15} \\
\hline & Fairbanks & 4.8 & 3.1 & 50.8 & -68.4 & \\
\hline & Innsbruck & 7.5 & 3.7 & 101.2 & -50.1 & \\
\hline \multirow{3}{*}{$\operatorname{Acc}(m)$} & Cairns & 1.0 & 0.8 & 18.5 & -46.8 & \multirow{3}{*}{1.87} \\
\hline & Fairbanks & 0.8 & 0.7 & 14.2 & -55.8 & \\
\hline & Innsbruck & 1.1 & 0.8 & 39.1 & -43.0 & \\
\hline
\end{tabular}

The integration of three different constellations allows the three procedures to satisfy the LPV-200 requirements with at least $40 \%$ of margin in nominal conditions.
As mentioned previously, different combinations of the three constellations have been examined, but because of their similar trend to the above configurations, we only report the summary tables.

- Scenario: Galileo 24 SV

TABLE VIII. PERFormance COMPARISON GALILEO 24SV CONFIGURATION

\begin{tabular}{|c|c|c|c|c|c|c|}
\hline Param. & Location & $\begin{array}{c}\text { Max } \\
\text { Body } \\
\text { Ref }\end{array}$ & $\begin{array}{l}\text { ENU } \\
\text { value }\end{array}$ & $\begin{array}{c}\text { SBody } \\
- \\
\text { ENU\% }\end{array}$ & $\triangle A L \%$ & $A L$ \\
\hline \multirow{3}{*}{$\begin{array}{l}\text { HPL } \\
\text { (m) }\end{array}$} & Cairns & 14.6 & 8.6 & 68.9 & -63.6 & \multirow{3}{*}{40} \\
\hline & Fairbanks & 16.4 & 10.9 & 47.7 & -59.9 & \\
\hline & Innsbruck & 206.4 & 20.5 & 908.6 & 415.9 & \\
\hline \multirow{3}{*}{ VPL (m) } & Cairns & 23.1 & 13.6 & 70.0 & -34.0 & \multirow{3}{*}{35} \\
\hline & Fairbanks & 14.4 & 12.7 & 13.8 & -58.8 & \\
\hline & Innsbruck & 677.0 & 20.8 & 3158 & 1834 & \\
\hline \multirow{3}{*}{$\begin{array}{l}\text { EMT } \\
\text { (m) }\end{array}$} & Cairns & 9.0 & 5.1 & 75.5 & -40.1 & \multirow{3}{*}{15} \\
\hline & Fairbanks & 5.5 & 4.8 & 14.1 & -63.6 & \\
\hline & Innsbruck & 322.7 & 8.8 & 3561 & 2052 & \\
\hline \multirow{3}{*}{$\operatorname{Acc}(m)$} & Cairns & 1.92 & 1.3 & 52.6 & 2.5 & \multirow{3}{*}{1.87} \\
\hline & Fairbanks & 1.2 & 1.1 & 5.9 & -38.0 & \\
\hline & Innsbruck & 2.1 & 1.5 & 36.6 & 10.2 & \\
\hline
\end{tabular}

- Scenario: Galileo $27 \mathrm{SV}$

TABLE IX

PeRFoRMANCE COMPARISON FOR THE GALILEO 27 SV CONFIGURATION

\begin{tabular}{|c|c|c|c|c|c|c|}
\hline Param. & Location & $\begin{array}{c}\text { Max } \\
\text { Body } \\
\text { Ref }\end{array}$ & $\begin{array}{l}\text { ENU } \\
\text { value }\end{array}$ & $\begin{array}{c}\text { SBody } \\
- \\
\text { ENU\% }\end{array}$ & $\triangle A L \%$ & $A L$ \\
\hline \multirow{3}{*}{$\begin{array}{l}\text { HPL } \\
(\mathrm{m})\end{array}$} & Cairns & 14.6 & 8.6 & 68.9 & -63.6 & \multirow{3}{*}{40} \\
\hline & Fairbanks & 14.4 & 10.3 & 39.9 & -63.9 & \\
\hline & Innsbruck & 55.1 & 19.2 & 187.3 & 37.8 & \\
\hline \multirow{3}{*}{ VPL (m) } & Cairns & 23.1 & 13.6 & 70.0 & -34.0 & \multirow{3}{*}{35} \\
\hline & Fairbanks & 13.5 & 12.3 & 9.2 & -61.6 & \\
\hline & Innsbruck & 38.3 & 17.9 & 144.2 & 9.3 & \\
\hline \multirow{3}{*}{$\begin{array}{l}\text { EMT } \\
\text { (m) }\end{array}$} & Cairns & 9.0 & 5.1 & 75.5 & -40.1 & \multirow{3}{*}{15} \\
\hline & Fairbanks & 5.7 & 4.7 & 10.9 & -64.9 & \\
\hline & Innsbruck & 17.1 & 6.9 & 148.8 & 14.2 & \\
\hline \multirow{3}{*}{$\operatorname{Acc}(m)$} & Cairns & 1.92 & 1.3 & 52.6 & 2.5 & \multirow{3}{*}{1.87} \\
\hline & Fairbanks & 1.1 & 1.1 & 0.0 & -41.0 & \\
\hline & Innsbruck & 2.0 & 1.5 & 36.5 & 7.0 & \\
\hline
\end{tabular}




\section{- Scenario: GLONASS}

TABLE $X$ PERFORMANCE COMPARISON FOR THE GLONASS CONFIGURATION

\begin{tabular}{|c|c|c|c|c|c|c|}
\hline Param. & Location & $\begin{array}{c}\text { Max } \\
\text { Body Ref }\end{array}$ & $\begin{array}{l}\text { ENU } \\
\text { value }\end{array}$ & $\begin{array}{c}\text { BBody } \\
- \\
\text { ENU\% }\end{array}$ & $\triangle A L \%$ & $A L$ \\
\hline \multirow{3}{*}{$\begin{array}{l}\text { HPL } \\
(\mathrm{m})\end{array}$} & Cairns & 26.1 & 26.1 & 0.0 & -34.8 & \multirow{3}{*}{40} \\
\hline & Fairbanks & 18.6 & 11.7 & 58.5 & -53.6 & \\
\hline & Innsbruck & 89.1 & 14.8 & 501.1 & 122.6 & \\
\hline \multirow{3}{*}{ VPL (m) } & Cairns & 36.3 & 36.3 & 0.0 & 3.7 & \multirow{3}{*}{35} \\
\hline & Fairbanks & 14.8 & 19.4 & 31.5 & -44.5 & \\
\hline & Innsbruck & 18.4 & 350.0 & 2178 & 900 & \\
\hline \multirow{3}{*}{$\begin{array}{l}\text { EMT } \\
(m)\end{array}$} & Cairns & 16.6 & 11.5 & 43.8 & 10.5 & \multirow{3}{*}{15} \\
\hline & Fairbanks & 9.2 & 6.0 & 52.3 & -38.6 & \\
\hline & Innsbruck & 178.9 & 6.7 & 2550 & 1092 & \\
\hline \multirow{3}{*}{$\operatorname{Acc}(\mathrm{m})$} & Cairns & 3.2 & 3.2 & 0.0 & 67.8 & \multirow{3}{*}{1.87} \\
\hline & Fairbanks & 1.6 & 1.4 & 14.6 & -13.9 & \\
\hline & Innsbruck & 2.6 & 1.4 & 88.7 & 40.3 & \\
\hline
\end{tabular}

- Scenario: GPS + Galileo $27 \mathrm{SV}$

TABLE XI. PERFORMANCE COMPARISON FOR THE GPS + GALILEO 27 SV CONFIGURATION

\begin{tabular}{|c|c|c|c|c|c|c|}
\hline Param. & Location & $\begin{array}{c}\text { Max } \\
\text { Body Ref }\end{array}$ & $\begin{array}{l}\text { ENU } \\
\text { value }\end{array}$ & $\begin{array}{c}\text { BBody } \\
- \\
\text { ENU\% }\end{array}$ & $\triangle A L \%$ & $A L$ \\
\hline \multirow{3}{*}{$\begin{array}{l}\text { HPL } \\
(\mathrm{m})\end{array}$} & Cairns & 12.3 & 10.3 & 19.3 & -69.3 & \multirow{3}{*}{40} \\
\hline & Fairbanks & 13.5 & 12.2 & 10.1 & -66.3 & \\
\hline & Innsbruck & 30.5 & 14.3 & 113.6 & -23.8 & \\
\hline \multirow{3}{*}{ VPL (m) } & Cairns & 21.4 & 13.1 & 63.2 & -38.8 & \multirow{3}{*}{35} \\
\hline & Fairbanks & 22.6 & 14.0 & 61.4 & -35.5 & \\
\hline & Innsbruck & 35.3 & 16.6 & 113.1 & 1.0 & \\
\hline \multirow{3}{*}{$\begin{array}{l}\text { EMT } \\
(m)\end{array}$} & Cairns & 8.6 & 4.8 & 79.7 & -42.9 & \multirow{3}{*}{15} \\
\hline & Fairbanks & 9.6 & 5.5 & 74.4 & -36.3 & \\
\hline & Innsbruck & 15.9 & 6.2 & 156.3 & 6.0 & \\
\hline \multirow{3}{*}{$\operatorname{Acc}(\mathrm{m})$} & Cairns & 0.9 & 1.07 & 19.6 & -42.8 & \multirow{3}{*}{1.87} \\
\hline & Fairbanks & 1.0 & 0.8 & 14.0 & -48.4 & \\
\hline & Innsbruck & 1.6 & 1.0 & 63.7 & -16.4 & \\
\hline
\end{tabular}

- $\quad$ Scenario: GPS + GLONASS

TABLE XII. PERFORMANCE COMPARISON FOR THE GPS + GLONASS CONFIGURATION

\begin{tabular}{|c|c|c|c|c|c|c|}
\hline Param. & Location & $\begin{array}{c}\text { Max } \\
\text { Body Ref }\end{array}$ & $\begin{array}{l}\text { ENU } \\
\text { value }\end{array}$ & $\begin{array}{c}\text { BBody } \\
- \\
\text { ENU\% }\end{array}$ & $\triangle A L \%$ & $A L$ \\
\hline \multirow{3}{*}{$\begin{array}{l}\text { HPL } \\
(\mathrm{m})\end{array}$} & Cairns & 11.8 & 11.1 & 6.3 & -70.5 & \multirow{3}{*}{40} \\
\hline & Fairbanks & 14.9 & 12.9 & 15.5 & -62.8 & \\
\hline & Innsbruck & 30.4 & 13.8 & 120.9 & -24.0 & \\
\hline \multirow{3}{*}{ VPL (m) } & Cairns & 29.5 & 29.5 & 0.0 & -15.8 & \multirow{3}{*}{35} \\
\hline & Fairbanks & 21.9 & 14.5 & 51.4 & -37.4 & \\
\hline & Innsbruck & 35.6 & 13.1 & 172.0 & 1.8 & \\
\hline \multirow{3}{*}{$\begin{array}{l}\text { EMT } \\
(m)\end{array}$} & Cairns & 13.2 & 13.2 & 0.0 & -12.8 & \multirow{3}{*}{15} \\
\hline & Fairbanks & 9.0 & 5.6 & 62.2 & -39.9 & \\
\hline & Innsbruck & 16.1 & 5.1 & 215.4 & 7.6 & \\
\hline \multirow{3}{*}{$\operatorname{Acc}(\mathrm{m})$} & Cairns & 1.3 & 1.1 & 10.3 & -32.7 & \multirow{3}{*}{1.87} \\
\hline & Fairbanks & 1.2 & 1.0 & 24.9 & -36.2 & \\
\hline & Innsbruck & 1.3 & 0.9 & 44.0 & -30.7 & \\
\hline
\end{tabular}

- Scenario: GLONASS + Galileo $24 \mathrm{SV}$

TABLE XIII.

PERFORMANCE COMPARISON FOR THE GLONASS + GALILEO 24 SV CONFIGURATION

\begin{tabular}{|c|c|c|c|c|c|c|}
\hline Param. & Location & $\begin{array}{c}\text { Max } \\
\text { Body Ref }\end{array}$ & $\begin{array}{l}\text { ENU } \\
\text { value }\end{array}$ & $\begin{array}{c}\Delta \text { Body } \\
- \\
\text { ENU\% }\end{array}$ & $\Delta A L \%$ & $A L$ \\
\hline \multirow{3}{*}{$\begin{array}{l}\text { HPL } \\
(\mathrm{m})\end{array}$} & Cairns & 11.5 & 11.5 & 0.0 & -71.2 & \multirow{3}{*}{40} \\
\hline & Fairbanks & 12.7 & 11.0 & 14.4 & -68.2 & \\
\hline & Innsbruck & 19.7 & 14.1 & 39.9 & -50.7 & \\
\hline \multirow{3}{*}{ VPL (m) } & Cairns & 29.3 & 29.3 & 0.0 & -16.4 & \multirow{3}{*}{35} \\
\hline & Fairbanks & 15.9 & 13.9 & 14.4 & -54.7 & \\
\hline & Innsbruck & 23.8 & 17.2 & 38.0 & -32.1 & \\
\hline \multirow{3}{*}{$\begin{array}{l}\text { EMT } \\
(\mathrm{m})\end{array}$} & Cairns & 13.1 & 13.1 & 0.0 & -13.0 & \multirow{3}{*}{15} \\
\hline & Fairbanks & 6.5 & 5.3 & 21.5 & -56.7 & \\
\hline & Innsbruck & 11.5 & 6.7 & 71.4 & -23.7 & \\
\hline \multirow{3}{*}{$\operatorname{Acc}(m)$} & Cairns & 1.5 & 1.1 & 35.3 & -18.3 & \multirow{3}{*}{1.87} \\
\hline & Fairbanks & 0.92 & 0.9 & 7.5 & -50.5 & \\
\hline & Innsbruck & 1.86 & 1.0 & 87.9 & -0.5 & \\
\hline
\end{tabular}


- Scenario: GLONASS + Galileo $27 \mathrm{SV}$

TABLE XIV. PERFORMANCE COMPARISON FOR THE GLONASS + GALILEO 27 SV CONFIGURATION

\begin{tabular}{|c|c|c|c|c|c|c|}
\hline Param. & Location & $\begin{array}{c}\text { Max } \\
\text { Body Ref }\end{array}$ & $\begin{array}{l}\text { ENU } \\
\text { value }\end{array}$ & $\begin{array}{c}\text { BBody } \\
- \\
\text { ENU\% }\end{array}$ & $\triangle A L \%$ & $A L$ \\
\hline \multirow{3}{*}{$\begin{array}{l}\text { HPL } \\
(\mathrm{m})\end{array}$} & Cairns & 11.5 & 11.5 & 0.0 & -71.2 & \multirow{3}{*}{40} \\
\hline & Fairbanks & 12.7 & 11.0 & 14.4 & -68.2 & \\
\hline & Innsbruck & 19.4 & 13.2 & 46.6 & -51.5 & \\
\hline \multirow{3}{*}{ VPL $(m)$} & Cairns & 29.3 & 29.3 & 0.0 & -16.4 & \multirow{3}{*}{35} \\
\hline & Fairbanks & 15.9 & 13.9 & 14.4 & -54.7 & \\
\hline & Innsbruck & 23.9 & 16.9 & 41.3 & -31.9 & \\
\hline \multirow{3}{*}{$\begin{array}{l}\text { EMT } \\
(m)\end{array}$} & Cairns & 13.1 & 13.1 & 0.0 & -13.0 & \multirow{3}{*}{15} \\
\hline & Fairbanks & 6.5 & 5.3 & 21.5 & -56.7 & \\
\hline & Innsbruck & 11.2 & 6.4 & 75.2 & -25.3 & \\
\hline \multirow{3}{*}{$\operatorname{Acc}(\mathrm{m})$} & Cairns & 1.5 & 1.1 & 35.3 & -18.3 & \multirow{3}{*}{1.87} \\
\hline & Fairbanks & 0.9 & 0.8 & 8.0 & -51.9 & \\
\hline & Innsbruck & 1.86 & 1.0 & 91.2 & -0.5 & \\
\hline
\end{tabular}

- Scenario: GPS + GLONASS + Galileo $27 \mathrm{SV}$

TABLE XV. PERFORMANCE COMPARISON FOR THE GPS + GLONASS + GALILEO 27 SV CONFIGURATION

\begin{tabular}{|c|c|c|c|c|c|c|}
\hline Param. & Location & $\begin{array}{c}\text { Max } \\
\text { Body Ref }\end{array}$ & $\begin{array}{l}\text { ENU } \\
\text { value }\end{array}$ & $\begin{array}{c}\text { SBody } \\
- \\
\text { ENU\% }\end{array}$ & $\triangle A L \%$ & $A L$ \\
\hline \multirow{3}{*}{$\begin{array}{l}\text { HPL } \\
(\mathrm{m})\end{array}$} & Cairns & 9.2 & 7.7 & 19.5 & -77.0 & \multirow{3}{*}{40} \\
\hline & Fairbanks & 11.4 & 9.7 & 15.3 & -72.2 & \\
\hline & Innsbruck & 19.8 & 11.2 & 76.7 & -50.4 & \\
\hline \multirow{3}{*}{ VPL (m) } & Cairns & 17.3 & 12.0 & 44.3 & -50.5 & \multirow{3}{*}{35} \\
\hline & Fairbanks & 12.6 & 9.6 & 31.4 & -63.9 & \\
\hline & Innsbruck & 18.4 & 10.5 & 74.9 & -47.5 & \\
\hline \multirow{3}{*}{$\begin{array}{l}\text { EMT } \\
\text { (m) }\end{array}$} & Cairns & 6.9 & 4.5 & 51.6 & -54.0 & \multirow{3}{*}{15} \\
\hline & Fairbanks & 4.9 & 3.3 & 47.7 & -67.5 & \\
\hline & Innsbruck & 7.4 & 3.7 & 100.4 & -50.4 & \\
\hline \multirow{3}{*}{$\operatorname{Acc}(m)$} & Cairns & 1.0 & 0.8 & 18.5 & -46.8 & \multirow{3}{*}{1.87} \\
\hline & Fairbanks & 0.8 & 0.7 & 13.6 & -56.7 & \\
\hline & Innsbruck & 1.1 & 0.8 & 39.8 & -43.1 & \\
\hline
\end{tabular}

\section{CONCLUSIONS}

It is clear from the graphs and the tables that the aircraft attitude and the surrounding environment affect the performance of the ARAIM algorithm; each satellite lost generates a peak in the performance parameters that depends on the total number of satellites in view, their relative geometry and on the number of satellites lost at the same time. The single GPS constellation configuration could not be enough to comply with the necessary requirements for LPV-200 approaches (the same results were obtained with GLONASS and Galileo individually). The dual constellation configuration seems to satisfy the requirements, but with limited margin with respect to the thresholds, which means that even a small variation in the nominal conditions could trigger an alarm. The main outcome of this research is the identification that the ideal scenario would be to have a tri-constellation system that provides at the same time high redundancy, reliability and increased safety margin.

However, further analysis showed that a single constellation could sometimes satisfy the LPV-200 RNP, since the performances are strongly dependent on both the satellite geometry, as one can easily deduce, and the models which are used to estimate signal errors and biases (e.g. ionospheric and tropospheric delays). Consequently, even the same trajectory, performed with a different starting time, could lead to completely different results.

These results show that a dedicated system, that evaluates the effects of the attitude and the surrounding environment in real time, needs to be developed and integrated into the flight management system if the ARAIM technique is to be used as an on-board system for integrity monitoring. Moreover, the results show that a dual-constellation GNSS receiver might not be sufficient for all of the possible scenarios, supporting the need for an international collaboration for the development of multi-GNSS applications.

\section{ACKNOWLEDGMENT}

The authors would like to thank Mr. John Wilde and Mr. Kieran Conlon of the DW International Ltd for supporting this work and for their helpful technical comments.

\section{REFERENCES}

[1] Federal Aviation Administration, Responsible office: AFS-400. Advisory Circular 90-100A - U.S Terminal and En Route Area Navigation (RNAV) Operations. March 2007.

[2] GEAS - Phase I Panel Report of the GNSS Evolutionary Architecture Study. Federal Aviation Administration (FAA). 2008

[3] GEAS - Phase II Report of the GNSS Evolutionary Architecture Study. Federal Aviation Administration (FAA). 2010

[4] WG-C - EU-U.S. Cooperation on Satellite Navigation - ARAIM Technical Subgroup - Interim Report. 2012

[5] B. S. Pervan, S. P. Pullen and J. R. Christie, "A Multiple Hypothesis Approach to Satellite Navigation Integrity", NAVIGATION, Journal of the Institute of Navigation, vol. 45, No. 1, pp 61-84, Spring 1998.

[6] A. Ene, "Multiple Hypothesis RAIM with Real-Time FDE and Forecasted Availability for Combined Galileo-GPS Vertical Guidance.", Proceedings of The European Navigation Conference - GNSS, May 2007 TimeNav, Geneva, Switzerland.

[7] A. Ene, J. Blanch, T. Walter and J.D. Powell, "Validation of Multiple Hypothesis RAIM Algorithm Using Dual-Frequency GNSS Signals." Proceedings of The European Navigation Conference - GNSS, April 2008 Toulouse Space Show, Toulouse, France. 
[8] A. Ene, "Utilization of Modernized Global Navigation Satellite Systems for Aircraft-Based Navigation Integrity.", Doctor of Philosophy, Stanford University, 2009.

[9] J. Blanch, M.J. Choi, T. Walter, P. Enge and K. Suzuki, "Prototyping Advanced RAIM for Vertical Guidance.”, Proceedings of the 23rd International Technical Meeting of The Satellite Division of the Institute of Navigation, pp 285-291, September 2010 Portland, OR.

[10] M. Choi, J. Blanch, D. Akos, L. Heng, G. Gao, T. Walter and P. Enge, "Demonstrations of Multi-constellation Advanced RAIM for Vertical Guidance Using GPS and GLONASS Signals.” Proceedings of the 24th International Technical Meeting of The Satellite Division of the Institute of Navigation, pp. 3227 - 3234, September 2011 Portland, OR.

[11] M. Choi, J. Blanch, T. Walter, D. Akos and P. Enge, "Evaluation of Multi-constellation Advanced RAIM for Vertical Guidance Using GPS and GLONASS Signals with Multiple Faults." Proceedings of the 25th International Technical Meeting of The Satellite Division of the Institute of Navigation, pp. 884-892, September 2012 Nashville, TN.

[12] A. El-Mowafy, "ARAIM for Vertical Guidance Using GPS and BeiDou", Journal of Global Positioning Systems, 12(1), pp. 28-37, 2013.

[13] K. Pham, T. Mchugh and F. Lorge, "Demonstration of Viability of ARAIM for LPV and LPV-200 Service Using Flight Data." Proceedings of the 2013 International Technical Meeting of The Institute of Navigation, pp 274-300, January 2013 San Diego, CA.

[14] J. Blanch, T. Walter, P. Enge, S. Wallner, F. Fernandez, R. Dellago, R. Ioannides, B. Pervan, I. Hernandez, B. Belabbas, A. Spletter and M. Rippl, "Critical Elements for Multi-Constellation Advanced RAIM." Navigation: Journal of The Institute of Navigation, 60(1), pp. 53-69, 2013.

[15] J. Blanch, T. Walter, P. Enge, S. Wallner, F. Fernandez, R. Dellago, R. Ioannides, B. Pervan, I. Hernandez, B. Belabbas, A. Spletter and M. Rippl, “A Proposal for Multi-constellation Advanced RAIM for Vertical Guidance. Proceedings of the 24th International Technical Meeting of The Satellite Division of the Institute of Navigation, September 20-23 2011 Portland, OR. pp. 2665-2680.
[16] J. Blanch, T. Walter, P. Enge, Y. Lee, B. Pervan and A. Spletter, "Advanced RAIM User Algorithm Description: Integrity Support Message Processing, Fault Detection, Exclusion, and Protection Level Calculation." Proceedings of ION GNSS 2012, pp. 2828-2849, September 2012 Nashville, TN.

[17] Stanford University, Matlab Algorithm Availability Simulation Tool (MAAST) [Online]. http://waas.stanford.edu/staff/maast/maast.html, 2012.

[18] M. Rippl, I. Martini, B. Belabbas, and M. Meurer, “ARAIM Operational Performance Tested in Flight." ION International Technical Meeting 2014. San Diego, CA.

[19] Stanford University, MAAST download website [Online]. Available: http://waas.stanford.edu/staff/maast/maast.html. 2014

[20] T.S. Kelso, Celestrack

[Online], https://celestrak.com/GPS/almanac/Yuma/

[21] NAVCEN. U.S. Department of Homeland Security, The Navigation Center of Excellence [Online], 1997.

[22] International Civil Aviation Organization (ICAO), Manual on Required Navigation Performance, 2nd ed, 1999.

[23] International Civil Aviation Organization (ICAO), Validated ICAO GNSS Standards and Recommended Practices (SARPS), 2000.

[24] International Civil Aviation Organization (ICAO), "Aeronautical Telecommunications", in Annex 10 to the Convention on International Civil Aviation International Standards and Recommended Practices (SARPs), Volume I (Radio Navigation Aids), Montreal, Canada, July 2007.

[25] National Aeronautics and Space Administration (NASA), Shuttle Radar Topography Mission (SRTM) [Online], http://www2.jpl.nasa.gov/srtm/, 2000.

[26] Wikipedia, Axes Conventions [Online], https://en.wikipedia.org/wiki/Axes_conventions . 